\title{
Trial and Settlement: A Study of High-Low Agreements
}

\section{Citation}

Prescott, J. J. "Trial and Settlement: A Study of High-Low Agreements." K. E. Spier and A. H. Yoon, co-authors. J. L. \& Econ. 57, no. 3 (2014): 699-746.

\section{Published Version}

http://repository.law.umich.edu/cgi/viewcontent.cgi?article=2485\&context=articles

\section{Permanent link}

http://nrs.harvard.edu/urn-3:HUL.InstRepos:30012817

\section{Terms of Use}

This article was downloaded from Harvard University's DASH repository, and is made available under the terms and conditions applicable to Other Posted Material, as set forth at http:// nrs.harvard.edu/urn-3:HUL.InstRepos:dash.current.terms-of-use\#LAA

\section{Share Your Story}

The Harvard community has made this article openly available.

Please share how this access benefits you. Submit a story.

Accessibility 


\title{
University of Michigan Law School University of Michigan Law School Scholarship Repository
}

2014

\section{Trial and Settlement: A Study of High-Low Agreements}

\author{
J.J.Prescott \\ University of Michigan Law School, jprescott@umich.edu \\ Kathryn E. Spier \\ Harvard University, kspier@law.harvard.edu \\ Albert Yoon \\ University of Toronto, albert.yoon@utoronto.ca
}

Follow this and additional works at: http://repository.law.umich.edu/articles

Part of the Courts Commons, Insurance Law Commons, Legal Remedies Commons, and the Litigation Commons

\section{Recommended Citation}

Prescott, J. J. "Trial and Settlement: A Study of High-Low Agreements." K. E. Spier and A. H. Yoon, co-authors. J. L. \& Econ. 57, no. 3 (2014): 699-746.

This Article is brought to you for free and open access by the Faculty Scholarship at University of Michigan Law School Scholarship Repository. It has been accepted for inclusion in Articles by an authorized administrator of University of Michigan Law School Scholarship Repository. For more information, please contact mlaw.repository@umich.edu. 


\title{
Trial and Settlement: A Study of High-Low Agreements
}

\author{
J.J. Prescott University of Michigan \\ Kathryn E. Spier Harvard University \\ Albert Yoon University of Toronto
}

\begin{abstract}
This article presents the first systematic theoretical and empirical study of highlow agreements in civil litigation. A high-low agreement is a private contract that, if signed by litigants before trial, constrains any plaintiff's recovery to a specified range. In our theoretical model, trial is both costly and risky. When litigants have divergent subjective beliefs and are mutually optimistic about their trial prospects, cases may fail to settle. In these cases, high-low agreements can be in litigants' mutual interest because they limit the risk of outlier awards while still allowing mutually beneficial speculation. Using claims data from a national insurance company, we describe the features of these agreements and empirically investigate the factors that may influence whether litigants discuss or enter into them. Our empirical findings are consistent with the predictions of the theoretical model. Other applications include the use of collars in mergers and acquisitions.
\end{abstract}

\section{Introduction}

In the summer of 2004, a semitrailer truck cruising at 65 miles per hour rearended a Ford pickup truck that was stopped in a line of traffic. The pickup truck was in flames as witnesses pulled the driver, Delbert Sanders, from the

The authors are grateful to the American Bar Association Litigation Research Fund and the Searle Center on Law, Regulation, and Economic Growth for supporting this research and would like to thank Richard Holden, a referee, James Dana, Andrew Daughety, John DiNardo, Jim Greiner, Sam Gross, Eric Helland, Louis Kaplow, Kyle Logue, Jennifer Reinganum, Jesse Rothstein, Steve Shavell, Jeff Smith, Kathy Zeiler, and seminar participants at the Harvard Law School, the National Bureau of Economic Research, the University of Michigan, the University of Tel Aviv, Columbia Law School, and the Searle Center's Research Symposium on Empirical Studies of Civil Liability (at Northwestern Law School). Spier acknowledges financial support from the John M. Olin Center for Law, Economics, and Business at the Harvard Law School and National Science Foundation grant SES-1155761. Yoon 
wreckage. The driver of the semitrailer, who had been searching for his dropped cell phone at the time of the accident, was unharmed. The semitrailer driver and his insurer admitted liability for the accident, but they disputed the alleged severity of Sanders's claimed back injury. Settlement negotiations reached an impasse-the defendants' offer of $\$ 500,000$ was far below the $\$ 1.3$ million that Sanders demanded. Both sides were shocked when the jury returned a $\$ 5.25$ million verdict. Sanders never received $\$ 5.25$ million, however. Instead, the defendants paid only $\$ 1.5$ million, all that was owed under a high-low agreement signed by the parties before the jury rendered its verdict. ${ }^{1}$

A high-low agreement is a contract "in which a defendant agrees to pay the plaintiff a minimum recovery in return for the plaintiff's agreement to accept a maximum amount regardless of the outcome of the trial" (Garner 2004, p. 746). ${ }^{2}$ High-low agreements allow both sides to hedge their bets and appear to have become increasingly popular over the last 30 years (McDonough 2005). ${ }^{3} \mathrm{Al}-$ though some lawyers and judges have expressed reservations about their use, ${ }^{4}$ high-low agreements have found significant support among litigants and legal practitioners, including judges. In the words of a Pennsylvania appeals judge, "As a tool commonly utilized in litigation, a high/low agreement guarantees a plaintiff a minimal recovery while concomitantly circumscribing a defendant's potential exposure. Court, counsel, and litigants favor them" (Thompson v. T.J. Whipple Const. Co., 985 A.2d 221, 229 [Pa. Super. Ct. 2009]). ${ }^{5}$

In this article, we present the first systematic study of high-low agreements in civil litigation, ${ }^{6}$ beginning with a theoretical model in which litigants can enter

would like to thank the Russell Sage Foundation and the Law School Admissions Council for their generous financial support. We would also like to thank Jennifer Allen, Grady Bridges, Pier DeRoo, Rachel Goldstein, Michael Gough, Seth Kingery, Ray Magnum, Jon Markman, Michael Mulvania, and Jesse Taylor for excellent research assistance. Any errors are our own.

${ }^{1}$ Their agreement specified a low of $\$ 300,000$ and a high of $\$ 1.5$ million. See Emerick (2007).

${ }^{2}$ A related form of agreement involves giving fact finders a choice between two awards. In highlow cases, however, fact finders often remain unaware of the agreement.

${ }^{3}$ In Cook County, Illinois, Judge Richard Elrod estimated that high-low agreements are discussed in 20-30 percent — and actually used in 10 percent — of the claims he sees. The exact origins of highlow agreements are unknown. A mid-1970s article by a New York State judge describes high-low agreements and their advantages to litigants, including risk reduction and avoidance of delay for appeals (Finz 1976).

${ }^{4}$ For example, according to one plaintiffs' attorney, a high-low agreement "reduces the whole concept of a judicial proceeding to a wager" and "make[s] a mockery of the system" (Riner 1989, p. B2). While typically enforceable, high-low agreements have received greater scrutiny in situations involving multiple defendants and minors. See Hoenig (2006) and Faley and Alonso (1998). See also McDonough (2005).

${ }^{5}$ High-low agreements are also featured in several state-sponsored alternative dispute resolution programs. For example, they are specifically defined and applied in the statutory language of California's expedited jury trial program, Cal. Civ. Proc. Code secs. 630.01(c), 630.03 (West), and in New York's summary jury trial program, N.Y. R. Kings SJT Rules 12, 17 (West). Survey information from Charleston County, North Carolina, suggests that "virtually all parties enter into a high-low agreement when opting for a [summary jury trial]." See Hannaford-Agor et al. (2012, p. 13).

${ }^{6}$ Coulson (1968) contains the first academic mention of high-low agreements. No detailed treatment of high-low agreements exists in either the legal or economics literatures, although articles briefly discuss them. See, for example, Gross and Syverud (1996, pp. 61-62). Because settlement 
into contracts prior to risky and costly trials. When both opposing litigants are optimistic about their chances at trial and when litigation costs are not too large, both parties would prefer to go to trial rather than settle. These litigants will not necessarily opt for a "naked" trial, however. A high-low agreement that places a ceiling and a floor on any damages award can be a prudent alternative to a naked trial when the risk from going to trial is large and at least one litigant is sufficiently risk averse. High-low agreements can serve these litigants' joint interests by limiting risk exposure at trial—thereby reducing the risk premiums they bear-while still allowing them to benefit from their confidence in their own cases.

We then explore the actual use of high-low agreements using claims data from a large national insurer. More than 5 percent of litigated claims in our sample involved discussions of high-low agreements, almost 4 percent had high-low agreements in place when they were resolved at trial or in arbitration, and hundreds of settled claims also involved high-low discussions or agreements. We demonstrate that litigants' behavior in our data set is consistent with the basic predictions of our model. In particular, claims that are expected to be low cost and highly volatile are more likely, relative to baseline probabilities, to involve high-low discussions and/or result in a high-low agreement during litigation. Importantly, we do not claim that litigants seek high-low agreements for the reasons that we identify-only that the patterns in the data are consistent with their doing so.

Our article contributes to the large literature on the resolution of litigation (surveys include Spier 2007; Daughety 2000; Cooter and Rubinfeld 1989; Hay and Spier 1998). Most civil cases in the United States settle out of court. In state courts, fewer than 4 percent of filed cases go to trial. In federal courts, the figure is closer to 2 percent (Ostrom et al. 2001, p. 29; Administrative Office of the U.S. Courts 2002, p. 154, table C-4). Opting out of formal litigation generally makes economic sense: litigation is expensive, time-consuming, and risky. Given the obvious advantages of settlement, most scholarship has focused on the factors that motivate most parties to settle yet result in some parties proceeding to trial, despite the costs and uncertainties of adjudication.

Beginning with the early theoretical work of Landes (1971), Posner (1973), and Gould (1973), commentators have suggested that settlement may fail when litigants have different subjective beliefs about the likely outcome at trial. ${ }^{7}$ More

discussions occur in private and litigants are protective of litigation-related information, the empirical study of high-low agreements is challenging. To our knowledge, disclosure of high-low agreements is not a codified requirement in any jurisdiction.

${ }^{7}$ This is the approach taken here. This so-called mutual-optimism framework has been used to explore the selection of cases for trial (Priest and Klein 1984), fee shifting (Shavell 1982), conflicts between lawyers and clients (Miller 1987), and bifurcation of trials (Landes 1993). It has also served as a foundation for empirical work on settlement (see Waldfogel 1998). Experimental and anecdotal evidence indicates that litigants tend to exhibit self-serving biases (Loewenstein et al. 1993). Plaintiffs may overestimate expected judgments at trial, while defendants may underestimate them. See BarGill (2006) on the strategic advantages of self-serving biases and Yildiz $(2003,2004)$ for more recent theoretical work on bargaining without common priors. 
recent work shows that cases may fail to settle when litigants are asymmetrically informed about certain aspects of the litigation (P'ng 1983; Bebchuk 1984; Reinganum and Wilde 1986; Nalebuff 1987; Spier 1992). An active empirical literature explores why and when litigants will settle out of court, examining, for example, the role of the damages at stake, litigants' appetites for risk, and the possibility of reputation effects. ${ }^{8}$ In these literatures, settlement is almost always viewed as a simple transfer payment from a defendant to a plaintiff in exchange for forgoing further pursuit of a claim. ${ }^{9}$ In contrast, we allow litigants to commit to future transfer payments that are conditional on an outcome at trial, and we show that partial settlements in the form of high-low agreements can serve the parties' joint interests. ${ }^{10}$

Our analysis may also provide insight into contracting practices outside of litigation, such as the use of collars in corporate merger agreements. Collars are common in stock mergers in which target shareholders are paid in bidders' stock. ${ }^{11}$ A fixed-exchange-ratio collar, for example, specifies a constant ratio of exchange over a prespecified range of bidder stock prices-with restrictions outside of this range. To illustrate, when First Union bid to acquire BancFlorida in 1994, it promised BancFlorida's shareholders .669 of a share of its stock for each BancFlorida share if First Union's stock price was between $\$ 41.875$ and $\$ 44.875$. If the stock was trading below $\$ 41.875$ or above $\$ 44.875$, however, shareholders would instead receive $\$ 28$ or $\$ 30$ worth of stock per share, respectively. ${ }^{12}$ Thus, BancFlorida shareholders were assured between $\$ 28$ and $\$ 30$ per share, with the exact price in that range determined by First Union's stock value at the time of the transaction. Following the logic of our article, we see that fixed-exchange-ratio collars may allow both the bidder and target share-

\footnotetext{
${ }^{8}$ For examples of this work, see Danzon and Lillard (1983), Farber and White (1991), Kessler et al. (1996), Fournier and Zuehlke (1996), Fenn and Rickman (1999), Viscusi (1988), and Kessler and Rubinfeld (2004). Sieg (2000) and Watanabe (2005) present structural econometric models of settlement. Yoon (2004), Snyder and Hughes (1990), and Hughes and Snyder (1995) explore the effects of various tort reforms. Other work examines the selection effects at trial. See Waldfogel (1995), Kessler et al. (1996), Eisenberg and Farber (1997), and Siegelman and Waldfogel (1999).

${ }^{9}$ A notable exception is a literature that applies the mechanism design techniques of Myerson (1979) and Myerson and Satterthwaite (1983) to settlement. Spier (1994) and Klement and Neeman (2005) consider direct-revelation mechanisms, where the transfer payments depend on the litigants' pretrial announcements as well as the outcome at trial. Legal scholars have cautioned against the use of the trial-settlement dichotomy (Eisenberg and Lanvers 2008; Clermont and Schwab 2008; Hadfield 2004).

${ }^{10}$ Donohue (1991) studies the idea that parties who are not content with the fee-shifting rule in their jurisdiction can privately contract for an alternative rule. He notes, however, the dearth of evidence of these contracts in practice. We find ample real-world evidence of high-low agreements.

${ }^{11}$ There is a large literature exploring the choice between cash offers and stock offers in mergers and acquisitions. Myers and Majluf (1984) argue that bidders will make a stock offer when they believe their stock to be overvalued; Hansen (1987) argues that stock offers can mitigate the lemons problem when targets are privately informed. Relatively little has been written on collars, however. Using data on abnormal bidder returns at the time of merger announcements, Houston and Ryngaert (1997) argue that the use of collars is consistent with the asymmetric-information theories. See also Fuller (2003) and Officer (2004).

${ }^{12}$ See BancFlorida Financial Corporation, 8-K filing with Securities and Exchange Comm'n (January 17, 1994). Officer (2004) also uses this example and describes other types of collars as well.
} 
holders to speculate on the basis of their divergent priors about the future price of the bidder's stock (owing perhaps to different beliefs about any synergies resulting from the merger) while at the same time insulating potentially risk averse parties (for example, large block shareholders or owners of closely held target firms) from bearing excessive risk from the transaction. ${ }^{13}$

We begin the rest of the article in the next section by augmenting the standard out-of-court settlement model to allow litigants to modify future trial outcomes by contract, and we identify the conditions under which parties would prefer high-low agreements. Section 3 describes our insurance litigation data. Section 4 examines whether the patterns in high-low discussions and agreements in our data are consistent with our model's predictions. Section 5 extends our model by showing that litigants can also use high-low agreements to prevent the excessive rent seeking that can occur when litigation costs are endogenous and offsetting in their effects on expected trial outcomes. Section 6 concludes.

\section{The Model}

Two litigants, a plaintiff and a defendant, engage in settlement negotiations prior to a risky civil trial. If negotiations fail, the case proceeds to trial, where the court enters a judgment for either high damages, $x_{\mathrm{H}}$, or low damages, $x_{\mathrm{L}}$, where $x_{\mathrm{H}}>x_{\mathrm{L}}$. The plaintiff and defendant assess the probability of an award of high damages before settlement negotiations. The plaintiff believes that this probability is $\pi_{\mathrm{p}} \in[0,1]$, while the defendant believes that it is $\pi_{\mathrm{d}} \in[0,1]$. These beliefs are subjective and may diverge from one another. When $\pi_{\mathrm{p}}>\pi_{\mathrm{d}}$ the litigants are mutually optimistic about their lawsuit, and when $\pi_{\mathrm{p}}<\pi_{\mathrm{d}}$ the litigants are mutually pessimistic. The plaintiff's and defendant's preferences are represented by constant absolute risk aversion (CARA) expected utility functions $u_{\mathrm{p}}(x)=-\exp \left(-a_{\mathrm{p}} x\right)$ and $u_{\mathrm{d}}(x)=-\exp \left(-a_{\mathrm{d}} x\right)$, where $a_{\mathrm{p}}$ and $a_{\mathrm{d}}$ are the coefficients of absolute risk aversion, ${ }^{14}$ although all results continue to hold when one of the litigants (for example, the defendant) is risk neutral. ${ }^{15}$ The litigation costs of the plaintiff and defendant are $c_{\mathrm{p}}$ and $c_{\mathrm{d}}$, respectively. The damages, beliefs, preferences, and costs are all assumed to be common knowledge.

Contracts signed before trial may take one of two forms. An ordinary settlement contract is a simple transfer payment, $s$, from the defendant to the plaintiff.

\footnotetext{
${ }^{13}$ Interest rate collars in loan agreements, in which the borrower's interest rate is permitted to float between a ceiling and a floor, provide another example. See Briys et al. (1991).

${ }^{14}$ See Farmer and Pecorino (1994) and Heyes et al. (2004) for settlement models with risk-averse parties. Constant absolute risk aversion functions, commonly used in finance and macroeconomics, allow no income or wealth effects, generating straightforward comparative statics, as litigation costs drop out when calculating the optimal agreement.

${ }^{15}$ Large insurers are diversified across claims and may be considered risk neutral. Formally, this is captured in the limit as $a_{\mathrm{d}}$ approaches 0 . Interestingly, one can view the provision of high-low contracts to plaintiffs as a natural extension of their core business of providing insurance to others.
} 
By agreeing to settle, litigants can avoid both the risk and costs of trial. ${ }^{16} \mathrm{Al}-$ ternatively, litigants may negotiate an award-modification contract that specifies two payments, $s_{\mathrm{H}}$ and $s_{\mathrm{L}}$. In particular, when the court awards high damages, the defendant agrees to pay $s_{\mathrm{H}}$ under the contract to the plaintiff instead of $x_{\mathrm{H}}$. Similarly, when the court awards low damages, the defendant agrees to pay $s_{\mathrm{L}}$ to the plaintiff instead of $x_{\mathrm{L}}$. Negotiating award-modification contracts may be costly: in addition to bearing the litigation costs at trial, $c_{\mathrm{p}}$ and $c_{\mathrm{d}}$, the parties incur costs $k_{\mathrm{p}}$ and $k_{\mathrm{d}}$ when they negotiate an award-modification contract.

A Pareto-optimal award-modification contract would satisfy

$$
\frac{\left(\pi_{\mathrm{p}}\right) u_{\mathrm{p}}^{\prime}\left(s_{\mathrm{H}}-c_{\mathrm{p}}-k_{\mathrm{p}}\right)}{\left(1-\pi_{\mathrm{p}}\right) u_{\mathrm{p}}^{\prime}\left(s_{\mathrm{L}}-c_{\mathrm{p}}-k_{\mathrm{p}}\right)}=\frac{\left(\pi_{\mathrm{d}}\right) u_{\mathrm{d}}^{\prime}\left(-s_{\mathrm{H}}-c_{\mathrm{d}}-k_{\mathrm{d}}\right)}{\left(1-\pi_{\mathrm{d}}\right) u_{\mathrm{d}}^{\prime}\left(-s_{\mathrm{L}}-c_{\mathrm{d}}-k_{\mathrm{d}}\right)} .
$$

Equation (1) defines a locus of points, $\left(s_{\mathrm{H}}, s_{\mathrm{L}}\right)$, where the litigants' indifference curves are tangent to each other. ${ }^{17}$ Note that if $\pi_{\mathrm{p}}=\pi_{\mathrm{d}}$, then Pareto optimality implies $s_{\mathrm{H}}=s_{\mathrm{L}}$. When the litigants have the same beliefs, it is jointly optimal for them to insure each other fully against the risk at trial. Lemma 1 characterizes the set of Pareto-optimal modification contracts when litigants have potentially different beliefs (see Appendix B for a proof).

Lemma 1. With CARA expected utility, the set of unconstrained Paretooptimal award-modification contracts satisfy $s_{\mathrm{H}}-s_{\mathrm{L}}=\Delta^{*}$, where

$$
\Delta^{*}=\left(\frac{1}{a_{\mathrm{p}}+a_{\mathrm{d}}}\right) \ln \left[\frac{\left(1 / \pi_{\mathrm{d}}\right)-1}{\left(1 / \pi_{\mathrm{p}}\right)-1}\right] .
$$

The implications of equation (2) are intuitive. When litigants are very risk averse, meaning $a_{\mathrm{p}}+a_{\mathrm{d}}$ is large, then $s_{\mathrm{L}}$ and $s_{\mathrm{H}}$ will be close together, which reflects the strong desire for insurance by the parties. Conversely, when litigants are not very averse to risk, so $a_{\mathrm{p}}+a_{\mathrm{d}}$ is small, then $s_{\mathrm{L}}$ and $s_{\mathrm{H}}$ will be far apart.

Equation (2) also implies that when litigants are mutually optimistic $\left(\pi_{\mathrm{p}}>\right.$ $\pi_{\mathrm{d}}$ ), they have an incentive to speculate or gamble on the outcome at trial by increasing the stakes at the margin: the plaintiff receives a higher contractual payout when actual damages are found to be high instead of low $\left(s_{\mathrm{H}}-s_{\mathrm{L}}>0\right)$. When litigants are mutually pessimistic $\left(\pi_{\mathrm{p}}<\pi_{\mathrm{d}}\right)$, this ordering is reversed: the contract specifies a higher payout to the plaintiff when the court finds that

\footnotetext{
${ }^{16}$ Note that if litigants have the same subjective assessment of the probability that the plaintiff will win, then they would be jointly better off settling out of court for the expected damages, $s=$ $\pi x_{\mathrm{H}}+(1-\pi) x_{\mathrm{L}}$. If the parties are both sufficiently optimistic about their own cases, so $\pi_{\mathrm{p}}$ is significantly higher than $\pi_{\mathrm{d}}$, then there may be no ordinary settlement contract, $s$, that makes both the plaintiff and the defendant better off.

${ }^{17}$ Given their (possibly divergent) beliefs, neither litigant could be made subjectively better off without making the other litigant subjectively worse off. Equation (1) results if the plaintiff has the bargaining power and chooses $s_{\mathrm{H}}$ and $s_{\mathrm{L}}$ to maximize $\pi_{\mathrm{p}} u_{\mathrm{p}}\left(s_{\mathrm{H}}-c_{\mathrm{p}}-k_{\mathrm{p}}\right)+\left(1-\pi_{\mathrm{p}}\right) u_{\mathrm{p}}\left(s_{\mathrm{L}}-c_{\mathrm{p}}-k_{\mathrm{p}}\right)$, subject to $\pi_{\mathrm{d}} u_{\mathrm{d}}\left(-s_{\mathrm{H}}-c_{\mathrm{d}}-k_{\mathrm{d}}\right)+\left(1-\pi_{\mathrm{d}}\right) u_{\mathrm{d}}\left(-s_{\mathrm{L}}-c_{\mathrm{d}}-k_{\mathrm{d}}\right) \geq \pi_{\mathrm{d}} u_{\mathrm{d}}\left(-x_{\mathrm{H}}-c_{\mathrm{d}}-k_{\mathrm{d}}\right)+\left(1-\pi_{\mathrm{d}}\right) u_{\mathrm{d}}\left(-x_{\mathrm{L}}\right.$ $-c_{\mathrm{d}}-k_{\mathrm{d}}$ ). It would also be obtained if the defendant has the bargaining power and chooses the terms to maximize his expected utility subject to the plaintiff s individual rationality constraint.
} 
damages are low and a lower payout when actual damages are found to be high $\left(s_{\mathrm{H}}-s_{\mathrm{L}}<0\right) .{ }^{18}$ Contracts with $s_{\mathrm{H}}-s_{\mathrm{L}}<0$ might lead litigants to sabotage their own cases, however, and may therefore be unwise in practice.

In order to focus attention on realistic award-modification contracts, we impose the following contractual restriction:

Assumption 1. We assume $x_{\mathrm{L}} \leq s_{\mathrm{L}} \leq s_{\mathrm{H}} \leq x_{\mathrm{H}}$.

This assumption allows for many contracts that we observe in practice. It permits ordinary settlement agreements where $s_{\mathrm{L}}=s_{\mathrm{H}}$; high-low agreements in which the defendant agrees to a higher award in the low state, $s_{\mathrm{L}}>x_{\mathrm{L}}$, if the plaintiff agrees to a lower award in the high state, $s_{\mathrm{H}}<x_{\mathrm{H}}$; and no agreement at all, in which $s_{\mathrm{L}}=x_{\mathrm{L}}$ and $s_{\mathrm{H}}=x_{\mathrm{H}}$. This assumption does rule out contracts in which $s_{\mathrm{L}}>s_{\mathrm{H}}$, however, because such contracts would distort incentives, encouraging litigants to sabotage their own cases. Assumption 1 also eliminates contracts that amplify trial risk by making the high outcome, $s_{\mathrm{H}}$, even higher than the actual damages in the high state, $x_{\mathrm{H}}$, or by making $s_{\mathrm{L}}$ lower than the low-state damages, $x_{\mathrm{L}} \cdot{ }^{19}$

We now characterize the litigants' jointly optimal decision to settle out of court or proceed to trial, either with a high-low contract (that specifies how any damages award would be modified) in place or without any contract at all. In the proposition, the function $\phi\left(x_{\mathrm{H}}-x_{\mathrm{L}}\right)$, which is defined and described in Appendix B, captures the joint benefit of the plaintiff and the defendant from trial without an award-modification contract. ${ }^{20}$

Proposition 1. If the litigants are mutually pessimistic, $\pi_{\mathrm{p}} \leq \pi_{\mathrm{d}}$, then they settle out of court for a fixed amount. If the litigants are mutually optimistic, $\pi_{\mathrm{p}}>\pi_{\mathrm{d}}$, then a trial may occur.

a) If $x_{\mathrm{H}}-x_{\mathrm{L}} \leq \tilde{\Delta}$, where $\tilde{\Delta}>\Delta^{*}$ is defined by $\phi(\tilde{\Delta})=\phi\left(\Delta^{*}\right)-\left(k_{\mathrm{p}}+k_{\mathrm{d}}\right)$, then the litigants proceed to trial without any modification of the court's award when $c_{\mathrm{p}}+c_{\mathrm{d}} \leq \phi\left(x_{\mathrm{H}}-x_{\mathrm{L}}\right)$ and settle out of court for a fixed amount otherwise.

\footnotetext{
${ }^{18}$ In the extreme case of $\pi_{\mathrm{p}}=0$ and $\pi_{\mathrm{d}}=1$, the plaintiff and defendant would blissfully agree to a contract that had $s_{\mathrm{L}}=\infty$ and $s_{\mathrm{H}}=-\infty$.

${ }^{19}$ Optimistic, risk-neutral litigants would certainly want to amplify risk-indeed, they would want to spread the awards as far apart as possible. Some degree of amplification would be jointly desirable even for risk-averse parties when a plaintiff believes that it is much more likely that the court will award high damages than a defendant does. Imagine an extreme case in which both parties believe with certainty that they will prevail and so sign a contract with $s_{\mathrm{L}}=0<x_{\mathrm{L}}$ and $s_{\mathrm{H}}=2 x_{\mathrm{H}}>x_{\mathrm{H}}$. The defendant pays 0 in expectation, and the plaintiff expects twice as much as she would have otherwise received. Indeed, with these extreme beliefs and absent liquidity constraints, the litigants would agree to $s_{\mathrm{L}}=-\infty$ and $s_{\mathrm{H}}=\infty$. Such contracts might violate antigambling statutes or face other legal barriers when attempts at enforcement are made, but betting on lawsuit outcomes is not purely hypothetical. Jolly (1928) describes how the taxation of such wagers was a source of revenue for the judiciary under ancient Hindu law. See Donohue (1991) for a discussion of these issues in the context of contracting over the allocation of legal fees.

${ }^{20}$ This function takes on a value of 0 when $x_{\mathrm{H}}-x_{\mathrm{L}}=0$ and reaches its maximum value $\phi\left(\Delta^{*}\right)$ when $x_{\mathrm{H}}-x_{\mathrm{L}}=\Delta^{*}$ as defined in lemma 1. The parties prefer a costly trial to any out-of-court settlement when $c_{\mathrm{p}}+c_{\mathrm{d}} \leq \phi\left(x_{\mathrm{H}}-x_{\mathrm{L}}\right)$.
} 


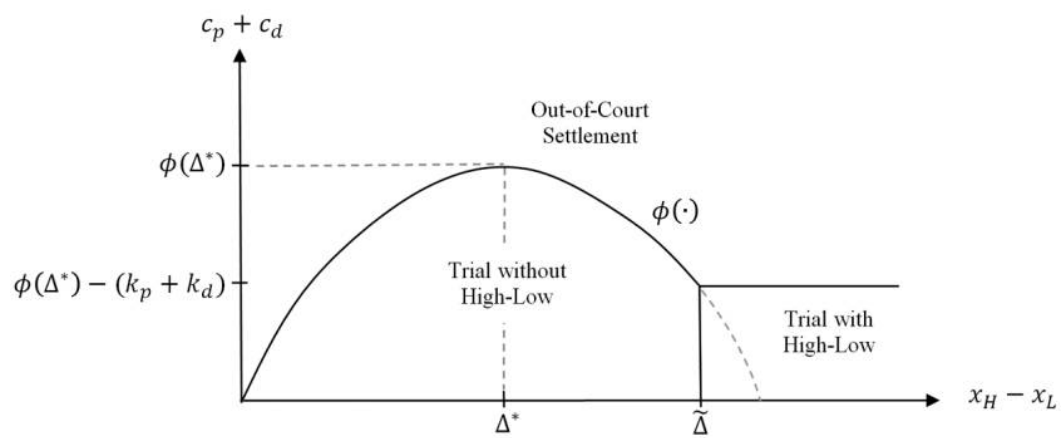

Figure 1. Theoretical predictions

b) If $x_{\mathrm{H}}-x_{\mathrm{L}}>\tilde{\Delta}$, then the litigants proceed to trial with a high-low contract specifying $s_{\mathrm{H}}-s_{\mathrm{L}}=\Delta^{*}$ when $c_{\mathrm{p}}+c_{\mathrm{d}}+k_{\mathrm{p}}+k_{\mathrm{d}} \leq \phi\left(\Delta^{*}\right)$ and settle out of court for a fixed amount otherwise.

Assumption 1 prevents mutually pessimistic litigants (those with $\pi_{\mathrm{p}}<\pi_{\mathrm{d}}$ ) from "shorting their own stock" with contracts with $s_{\mathrm{H}}<s_{\mathrm{L}}$, so mutually pessimistic litigants will never go to trial. These cases will simply settle out of court. If the litigants are mutually optimistic, however, some sort of trial may occur. In proposition $1 a$, the risk associated with a naked trial, $x_{\mathrm{H}}-x_{\mathrm{L}}$, is relatively small, and so the optimistic litigants gladly bear the full risk associated with a naked trial when the total litigation costs, $c_{\mathrm{p}}+c_{\mathrm{d}}$, are smaller than the joint gross benefit from naked litigation, $\phi\left(x_{\mathrm{H}}-x_{\mathrm{L}}\right){ }^{21}$ In proposition $1 b$, where the risk associated with a naked trial, $x_{\mathrm{H}}-x_{\mathrm{L}}$, is large, the litigants choose to limit this risk through a high-low contract with $s_{\mathrm{H}}-s_{\mathrm{L}}=\Delta^{*}$. The mutually optimistic litigants proceed to trial when their joint transaction costs, $c_{\mathrm{p}}+c_{\mathrm{d}}+k_{\mathrm{p}}+k_{\mathrm{d}}$, are smaller than the joint gross benefit from going to trial with an optimal high-low contract, $\phi\left(\Delta^{*}\right) .^{22}$

Figure 1 depicts the results of proposition 1 when litigants are mutually optimistic, $\pi_{\mathrm{p}}>\pi_{\mathrm{d} \cdot} \cdot{ }^{23}$ Cases settle out of court when the litigation costs, $c_{\mathrm{p}}+c_{\mathrm{d}}$, are

\footnotetext{
${ }^{21}$ Assumption 1 prevents these litigants from amplifying the risk at trial.

${ }^{22}$ If $k_{\mathrm{p}}+k_{\mathrm{d}}>\phi\left(\Delta^{\star}\right)$, then this condition is not satisfied for any $c_{\mathrm{p}}$ and $c_{\mathrm{d}}$ and so litigants will refuse to enter into high-low contracts.

${ }^{23}$ When $x_{\mathrm{H}}-x_{\mathrm{L}}=0$, the litigants' joint benefit of a naked trial is $0, \phi(0)=0$. As the spread $x_{\mathrm{H}}-x_{\mathrm{L}}$ increases, naked trials become more risky for both litigants, creating both benefits and additional costs for them. The larger spread is jointly beneficial ex ante because the parties are mutually optimistic and so there are mutual gains from trade from speculating at trial. At the same time, the litigants are made relatively worse off by the increased risk premium, which augments the direct costs of litigation. When $x_{\mathrm{H}}-x_{\mathrm{L}}$ is close to 0 and rising, the benefit of speculation initially grows faster than the risk premium (it is second order), so $\phi\left(x_{\mathrm{H}}-x_{\mathrm{L}}\right)$ is increasing. When $x_{\mathrm{H}}-$ $x_{\mathrm{L}}$ reaches $\Delta^{*}$, the risk premium is rising faster than the benefit from speculating at trial, so $\phi\left(x_{\mathrm{H}}-x_{\mathrm{L}}\right)$ is decreasing.
} 
large but proceed to trial when the litigation costs are small. Holding the litigation costs fixed, one can see that naked trials arise in an intermediate range where the spread $x_{\mathrm{H}}-x_{\mathrm{L}}$ is neither too high nor too low. When the spread $x_{\mathrm{H}}-x_{\mathrm{L}}$ exceeds a threshold $x_{\mathrm{H}}-x_{\mathrm{L}}>\tilde{\Delta}$, then parties proceed to trial with a high-low agreement. ${ }^{24}$ The next result follows immediately from proposition 1 and from the properties of the function $\phi\left(x_{\mathrm{H}}-x_{\mathrm{L}}\right)$.

Proposition 2. When $c_{\mathrm{p}}+c_{\mathrm{d}}$ rises, the likelihood of the parties agreeing to an out-of-court settlement increases and the likelihood of a trial (with or without a high-low agreement) falls. When $x_{\mathrm{H}}-x_{\mathrm{L}}$ rises, $(a)$ the likelihood of settlement falls when $x_{\mathrm{H}}-x_{\mathrm{L}}$ is small and rises when $x_{\mathrm{H}}-x_{\mathrm{L}}$ is large, $(b)$ the likelihood of a trial without a high-low agreement rises when $x_{\mathrm{H}}-x_{\mathrm{L}}$ is small and falls when $x_{\mathrm{H}}-x_{\mathrm{L}}$ is large, and $(c)$ the likelihood of a high-low agreement increases.

\section{Data Description}

The empirical study of settlement behavior is challenging because many parameters of interest (notably, appetites for risk and subjective beliefs) are unobservable; parties are small (making data collection difficult) or unwilling to share litigation-related information; and even when a public entity collects data on final outcomes, facts about underlying settlement negotiations and features of any agreement are rarely accessible. Our data, by contrast, consist of extensive proprietary information about all claims made to a large national auto and general liability insurer that closed between January 1, 2004, and March 31, 2009, beginning with the specifics of the underlying loss event, ending with the final resolution of the claim, and including comprehensive details about all disputes and any litigation. ${ }^{25}$

We extracted our data on high-low discussions and agreements from detailed narrative records that the insurer maintains (entered by both claim handlers and lawyers) on its management and resolution of each claim in dispute. ${ }^{26}$ Using a text-mining algorithm, we were able to identify claims that involved, at least on the insurer's side, some consideration of a high-low arrangement-including negotiations over high-low terms and even instances in which the insurer considered but decided against making a high-low proposal. ${ }^{27}$ For each of these claims, we recorded the context of the high-low conversation or deliberation,

\footnotetext{
${ }^{24}$ When $x_{\mathrm{H}}-x_{\mathrm{L}}=\Delta^{*}$, a high-low agreement provides no advantage over a naked trial since the trial outcome itself is Pareto optimal. When $x_{\mathrm{H}}-x_{\mathrm{L}} \in\left(\Delta^{*}, \tilde{\Delta}\right)$, the trial outcome is not Pareto optimal, but the additional costs of drafting the high-low agreement outweigh its benefits.

${ }^{25}$ The insurer insisted on anonymity as a condition of allowing us to use its data.

${ }^{26}$ Unfortunately, the insurer does not maintain electronic copies of its settlement or high-low agreements, nor any information about whether any high-low agreement was a written or oral contract. We obtained example copies of a number of the insurer's high-low agreements, redacted versions of which are available on request.

${ }^{27}$ See Appendix A for a description of the search algorithm, the information that we collected, the coding process that we employed, and the procedures that we used to ensure accuracy.
} 
whether the parties reached an agreement, the number of back-and-forth proposals, the relevant dates, and the proximity of the discussion to trial or arbitration, if apparent. In the event of an actual agreement, we recorded the high and low terms.

In these insurance cases, plaintiffs allege that injurers caused harm covered by the insurer's policies. If the plaintiff asserts damages within policy limits or declines to pursue the insured individually for any excess, the insurer effectively replaces the injurer as the defendant. Table 1 presents summary statistics for disputed claims with known resolutions, broken down by whether or not a claim involved high-low activity. ${ }^{28}$ As a group, the 935 cases involving high-low discussions and agreements took longer to conclude, ended with larger payouts, generated higher litigation costs for the insurer, and were less likely to involve a fatality or a corporate claimant than an average disputed claim, whether settled or litigated. ${ }^{29}$ Table 2 breaks down claims involving high-low activity into those involving just discussions and those involving actual agreements and, further, by how those claims were ultimately resolved (settlement or trial/arbitration). Of the 246 claims with high-low agreements, 99 were resolved at trial or in arbitration (an overall litigation rate of 40 percent). (There are five fewer claims in this table than in Table 1 because the final resolutions of five claims with high-low discussions are unknown.)

Table 3 reports claim, contract, and resolution details for the 246 claims in which the parties agreed to a high-low contract, including those that were subsequently settled out of court. Highs and lows average close to $\$ 161,000$ and $\$ 44,000$, respectively, and parties typically finalized their high-low agreements in the latter stages of these disputes. Although high-low agreements are clearly drafted in anticipation of trial or arbitration (indeed, as reflected in Table 2, approximately 100 of them went to a fact finder), litigants actually settled a majority of cases carrying high-low agreements prior to any adjudicated resolution. Finally, although our data include only limited information on the actual damages awarded by a fact finder, we do observe every insurer's payout. Most payments in the adjudicated high-low cases— 68 percent-fell between the upper

\footnotetext{
${ }^{28}$ Of the approximately 45,000 claims that were resolved without high-low activity, almost 2,500 claims (or about 5 percent) went to trial or arbitration. This class of litigated cases was more likely to include general liability claims, involved more corporate claimants, resulted in lower ultimate payouts, and involved higher litigation costs for the insurer when compared with the claims that settled without high-low activity. Table A1 provides additional information for all litigated claims $(n=2,636)$, for all claims involving a high-low discussion $(n=935)$, and for all claims involving a high-low agreement $(n=246)$. These groups overlap with each other.

${ }^{29}$ The relationship of the alleged harm to the policy limit can influence high-low discussions because a judgment that exceeds the policy limit places the policyholder at risk for the excess. However, insurers that refuse to settle for the policy limit typically pay any excess rather than risk liability for exercising bad faith in rejecting such an offer. See State Farm Auto Ins. v. Campbell, 538 U.S. 408 (2003).
} 
Table 1

Summary Statistics by Final Resolution and High-Low Activity for All Claims in Dispute

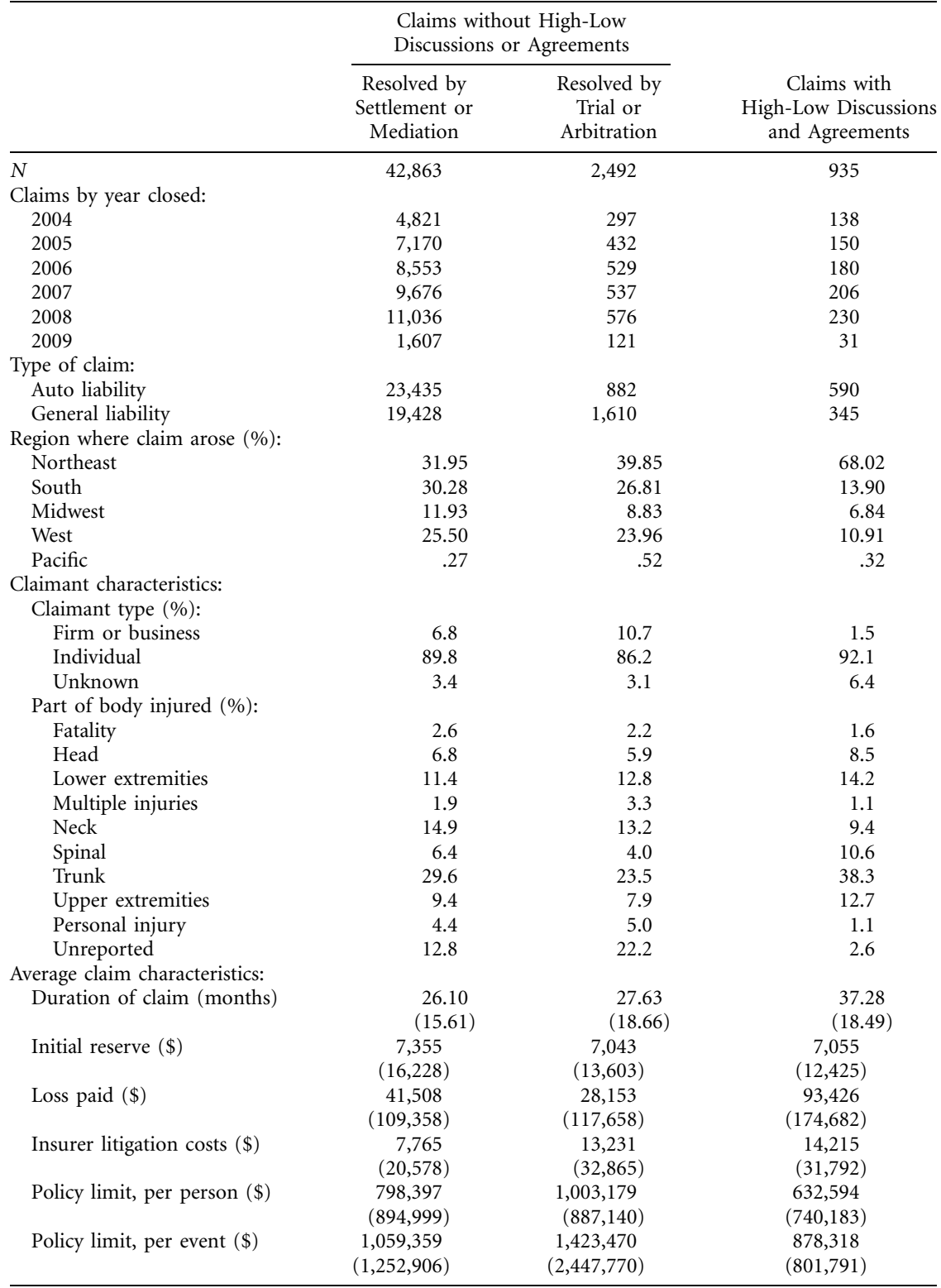

Note. Values are computed from machine data or litigation notes provided by the insurer. Financial values are reported in 2008 dollars. Standard deviations are in parentheses. 
Table 2

Summary Statistics by Final Resolution for All Claims with High-Low Discussions

\begin{tabular}{|c|c|c|c|c|}
\hline & \multicolumn{2}{|c|}{ Discussions Only } & \multicolumn{2}{|c|}{ Agreements } \\
\hline & $\begin{array}{l}\text { Settlement or } \\
\text { Mediation } \\
\text { (1) }\end{array}$ & $\begin{array}{c}\text { Trial or } \\
\text { Arbitration } \\
\text { (2) }\end{array}$ & $\begin{array}{l}\text { Settlement or } \\
\text { Mediation } \\
\text { (3) }\end{array}$ & $\begin{array}{c}\text { Trial or } \\
\text { Arbitration } \\
\quad(4)\end{array}$ \\
\hline$N$ & 639 & 45 & 147 & 99 \\
\hline \multicolumn{5}{|l|}{ Claims by year closed: } \\
\hline 2004 & 104 & 4 & 16 & 11 \\
\hline 2005 & 111 & 11 & 21 & 7 \\
\hline 2006 & 115 & 12 & 36 & 17 \\
\hline 2007 & 133 & 5 & 36 & 32 \\
\hline 2008 & 157 & 10 & 32 & 29 \\
\hline 2009 & 19 & 3 & 6 & 3 \\
\hline \multicolumn{5}{|l|}{ Type of claim: } \\
\hline Auto liability & 400 & 23 & 87 & 78 \\
\hline General liability & 239 & 22 & 60 & 21 \\
\hline \multicolumn{5}{|l|}{ Region where claim arose (\%): } \\
\hline Northeast & 68.23 & 60.00 & 72.11 & 63.64 \\
\hline South & 12.99 & 15.56 & 14.97 & 17.17 \\
\hline Midwest & 7.20 & 6.67 & 2.72 & 11.11 \\
\hline West & 11.42 & 15.56 & 10.20 & 7.07 \\
\hline Pacific & .16 & 2.22 & .00 & 1.01 \\
\hline \multicolumn{5}{|l|}{ Claimant characteristics: } \\
\hline \multicolumn{5}{|l|}{ Claimant type $(\%)$ : } \\
\hline Firm or business & 1.3 & .0 & 3.4 & 1.0 \\
\hline Individual & 93.3 & 84.4 & 91.8 & 89.9 \\
\hline Unknown & 5.5 & 15.6 & 4.8 & 9.1 \\
\hline \multicolumn{5}{|l|}{ Part of body injured (\%): } \\
\hline Fatality & 1.7 & 6.7 & .7 & .0 \\
\hline Head & 8.9 & 4.4 & 9.5 & 5.1 \\
\hline Lower extremities & 13.3 & 20.0 & 17.0 & 13.1 \\
\hline Multiple injuries & .9 & 6.7 & .7 & .0 \\
\hline Neck & 9.7 & 8.9 & 8.8 & 9.1 \\
\hline Spinal & 10.2 & 11.1 & 11.6 & 11.1 \\
\hline Trunk & 39.1 & 31.1 & 36.1 & 41.4 \\
\hline Upper extremities & 13.2 & 8.9 & 11.6 & 14.1 \\
\hline Personal Injury & .8 & .0 & 2.0 & 1.0 \\
\hline Unreported & 2.2 & 2.2 & 2.0 & 5.1 \\
\hline \multicolumn{5}{|l|}{ Average claim characteristics: } \\
\hline Duration of claim (months) & $\begin{array}{c}35.57 \\
(18.13)\end{array}$ & $\begin{array}{c}50.47 \\
(27.42)\end{array}$ & $\begin{array}{c}39.60 \\
(17.13)\end{array}$ & $\begin{array}{r}39.17 \\
(13.64)\end{array}$ \\
\hline Initial reserve $(\$)$ & $\begin{array}{c}7,318 \\
(13,084)\end{array}$ & $\begin{array}{l}10,945 \\
(18,015)\end{array}$ & $\begin{array}{c}6,501 \\
(10,805)\end{array}$ & $\begin{array}{c}4,468 \\
(4,531)\end{array}$ \\
\hline \multirow[t]{2}{*}{ Loss paid $(\$)$} & 92,201 & 150,415 & 89,140 & 85,980 \\
\hline & $(170,228)$ & $(337,284)$ & $(141,065)$ & $(139,191)$ \\
\hline \multirow[t]{2}{*}{ Insurer litigation costs $(\$)$} & 11,943 & 56,349 & 13,846 & 10,904 \\
\hline & $(26,340)$ & $(84,126)$ & $(25,296)$ & $(10,792)$ \\
\hline \multirow[t]{2}{*}{ Policy limit per person $(\$)$} & 664,752 & 643,792 & 627,319 & 416,004 \\
\hline & $(792,354)$ & $(545,772)$ & $(664,195)$ & $(509,241)$ \\
\hline \multirow[t]{2}{*}{ Policy limit per event $(\$)$} & 889,047 & $1,129,779$ & 936,635 & 588,551 \\
\hline & $(796,347)$ & $(879,138)$ & $(862,668)$ & $(624,862)$ \\
\hline
\end{tabular}

Note. Values are computed from machine data or litigation notes provided by the insurer. Financial values are reported in 2008 dollars. All claims involved a high-low discussion and are broken down by the claim's final high-low status and how the claim was ultimately resolved. Any high-low agreement is, by definition, no longer in force if the parties decide to renegotiate and fully settle. To be conservative, we assume that dozens of cases that involve high-low agreements settle when the insurer reports only that mediation or negotiation occurred (even though both can lead to some form of binding adjudication). Standard deviations are in parentheses. 
Table 3

Details of High-Low Agreements

\begin{tabular}{lc}
\hline & Value \\
\hline Total number of high-low agreements (complete) & 246 \\
Average duration from report date: & \\
High-low agreement reached (months) & 31.91 \\
& 14.8 \\
Claim closed (months) & 39.43 \\
& $(15.8)$ \\
High-low agreement details (\$): & 161,111 \\
Average high amount & $(223,198)$ \\
& 43,912 \\
Average low amount & $(107,645)$ \\
& \\
Resolution of high-low claims (\%): & 28.1 \\
Arbitration & 12.2 \\
Litigation & 56.9 \\
Settlement & 2.9 \\
Mediation & \\
Payout when claim adjudicated under high-low agreement (\%): & 15.2 \\
Final payout at the low end & 67.7 \\
Final payout between the high and low ends & 15.2 \\
Final payout at the high end & 2.0 \\
Unknown (\%) & \\
\hline
\end{tabular}

Note. Values are computed from machine data or litigation notes provided by the insurer. Financial values are reported in 2008 dollars. For $2 \%$ of the claims, high-low terms or payout information is missing, leaving the payout amount's relationship to the high and low terms unknown. Standard deviations are in parentheses.

and lower bounds, but payouts at the low and at the high ends in both cases happened in 15 percent of the claims. ${ }^{30}$

Table 4 displays information about the 935 claims in which the parties at a minimum discussed the possibility of entering into a high-low agreement. ${ }^{31}$ Unconditional averages across three types of these cases_claims in which the possibility of a high-low agreement was raised by one party, claims in which a high-low agreement was seriously discussed by both parties, and claims in which a high-low agreement was formally executed-reveal no particularly unusual differences or patterns, which suggests that, although claims that are candidates for high-low agreements may differ significantly from a typical claim in dispute, the line that separates claims in which a high-low agreement is simply suggested by a party from claims in which such a contract is signed may turn on chance circumstances.

\footnotetext{
${ }^{30}$ The coincidence that the proportion of cases paying out at the high end equals the proportion paying out at the low end does not imply that litigants are somehow equal in bargaining power, equally able to predict extreme outcomes, or even behaving rationally. Damages are bounded below (by 0), so an insurer's gains from a single binding high term might easily exceed the cost of paying out on dozens of binding low terms.

${ }^{31}$ The insurer at least internally discussed offering high-low terms in more than 300 additional claims (we found no evidence that any discussions with plaintiffs occurred in these cases).
} 
Table 4

Summary Statistics by Intensity of High-Low Discussion

\begin{tabular}{|c|c|c|c|}
\hline & $\begin{array}{l}\text { High-Low Raised } \\
\text { by One Party }\end{array}$ & $\begin{array}{l}\text { Parties Amenable } \\
\text { to High-Low }\end{array}$ & $\begin{array}{c}\text { High-Low Agreement } \\
\text { Reached }\end{array}$ \\
\hline$N$ & 345 & 344 & 246 \\
\hline \multicolumn{4}{|l|}{ Claims by year closed: } \\
\hline 2004 & 59 & 52 & 27 \\
\hline 2005 & 66 & 56 & 28 \\
\hline 2006 & 70 & 57 & 53 \\
\hline 2007 & 59 & 79 & 68 \\
\hline 2008 & 82 & 87 & 61 \\
\hline 2009 & 9 & 13 & 9 \\
\hline \multicolumn{4}{|l|}{ Type of claim: } \\
\hline Auto liability & 224 & 201 & 165 \\
\hline General liability & 121 & 143 & 81 \\
\hline \multicolumn{4}{|l|}{ Region where claim arose $(\%)$ : } \\
\hline Northeast & 70.43 & 65.12 & 68.70 \\
\hline South & 12.75 & 13.66 & 15.85 \\
\hline Midwest & 5.80 & 8.43 & 6.10 \\
\hline West & 10.72 & 12.50 & 8.94 \\
\hline Pacific & .29 & .29 & .41 \\
\hline \multicolumn{4}{|l|}{ Claimant characteristics: } \\
\hline \multicolumn{4}{|l|}{ Claimant type (\%): } \\
\hline Firm or business & 1.5 & .9 & 2.4 \\
\hline Individual & 91.0 & 93.9 & 91.1 \\
\hline Unknown & 7.5 & 5.2 & 6.5 \\
\hline \multicolumn{4}{|l|}{ Part of body injured (\%): } \\
\hline Fatality & 1.7 & 2.3 & .4 \\
\hline Head & 8.1 & 9.3 & 7.7 \\
\hline Lower extremities & 12.8 & 14.8 & 15.5 \\
\hline Multiple injuries & .6 & 2.0 & .4 \\
\hline Neck & 9.6 & 9.6 & 8.9 \\
\hline Spinal & 8.1 & 12.5 & 11.4 \\
\hline Trunk & 44.6 & 32.0 & 38.2 \\
\hline Upper extremities & 12.8 & 12.8 & 12.6 \\
\hline Personal injury & .3 & 1.5 & 1.6 \\
\hline Unreported & 1.5 & 3.2 & 3.3 \\
\hline \multicolumn{4}{|l|}{ Average claim characteristics: } \\
\hline Duration of claim (months) & $\begin{array}{c}35.36 \\
(20.77)\end{array}$ & $\begin{array}{c}37.68 \\
(17.69)\end{array}$ & $\begin{array}{c}39.43 \\
(15.79)\end{array}$ \\
\hline Initial reserve $(\$)$ & $\begin{array}{c}7,307 \\
(14,351)\end{array}$ & $\begin{array}{c}7,785 \\
(12,475)\end{array}$ & $\begin{array}{c}5,683 \\
(8,876)\end{array}$ \\
\hline \multirow[t]{2}{*}{ Loss paid (\$) } & 78,472 & 112,377 & 87,876 \\
\hline & $(147,138)$ & $(216,173)$ & $(140,041)$ \\
\hline \multirow[t]{2}{*}{ Insurer litigation costs $(\$)$} & 13,420 & 16,123 & 12,662 \\
\hline & $(37,407)$ & $(32,183)$ & $(20,736)$ \\
\hline \multirow[t]{2}{*}{ Policy limit per person $(\$)$} & 606,609 & 723,243 & 542,277 \\
\hline & $(618,820)$ & $(907,452)$ & $(614,334)$ \\
\hline \multirow[t]{2}{*}{ Policy limit per event $(\$)$} & 860,351 & 951,524 & 795,281 \\
\hline & $(788,358)$ & $(816,792)$ & $(791,954)$ \\
\hline
\end{tabular}

Note. Values are computed from machine data or litigation notes provided by the insurer. Financial values are reported in 2008 dollars. Claims with a high-low agreement raised by one party include claims in which either the insurer or the other party raised the possibility of a high-low agreement in a settlement discussion but the other side was uninterested, according to the litigation notes. Claims with parties amenable to a high-low agreement include claims in which the parties attempted to negotiate a high-low agreement at some point in the litigation. Standard deviations are in parentheses. 


\section{Empirical Strategy and Results}

We do not observe litigants' beliefs about likely damages awards, and we cannot directly measure their levels of risk aversion. As a result, we are unable to test the validity of our model directly. Comparative statics derived from the theoretical analysis in Section 2, however, demonstrate that if our theoretical account is valid, we may be able to detect its influence on settlement behavior. Consequently, our empirical strategy employs two of our model's conjectures about litigants' behavior under varying exogenous conditions to predict a particular pattern in how parties approach and resolve claims. ${ }^{32}$

First, our model suggests that when expected litigation costs are high, we should observe more settlement and fewer trials, including fewer high-low agreements, all else equal. Therefore, if the insurer's expected costs, $c_{\mathrm{d}}$, are high and $c_{\mathrm{d}}$ and $c_{\mathrm{p}}$ are not too negatively correlated, ${ }^{33}$ we should witness fewer trials. Second, when adjudication outcomes are sufficiently unpredictable (or the variance in the award or payout amount is high because its distribution has a larger spread-that is, $x_{\mathrm{H}}-x_{\mathrm{L}}$ is sufficiently large), we should see litigants considering, discussing, and entering into high-low agreements more often. ${ }^{34}$

Combining these two predictions, we can rank four categories of cases in terms of how likely they are to involve high-low discussions and agreements, from most likely to least likely: (1) cases with low expected litigation costs and high expected outcome variance (LC-HV), (2) cases with low expected litigation costs and low expected outcome variance (LC-LV) or with high expected litigation costs and high expected outcome variance (HC-HV), ${ }^{35}$ and finally (3) cases with high expected litigation costs and low expected outcome variance (HC-LV). In what follows, we examine whether behavior is consistent with this ranking by empirically evaluating the relative likelihood that parties will prefer high-low agreements to settlement or naked adjudication.

In carrying out this empirical work, we construct a proxy for expected litigation costs for each dispute using the actual litigation costs of cases with similar

\footnotetext{
${ }^{32}$ Demonstrating a causal relationship_that parties use high-low agreements to reduce riskassociated losses-requires more than a pattern in the data that is consistent with the model. We must also rule out all reasonable alternative explanations for the pattern. Although we are not aware of any obvious alternative explanations for what we find, our empirical claim must remain descriptive in nature.

${ }^{33}$ The condition $\operatorname{Corr}\left(c_{\mathrm{d}}, c_{\mathrm{p}}\right) \geq 0$ is sufficient and requires simply that litigation costs be weak complements, which is surely true in the vast majority of cases. Ideally, we would include expected $c_{\mathrm{p}}$ in our analysis, but we have data only from a single, repeat defendant.

${ }^{34}$ In a general model, risk-averse parties would attempt to reduce risk when damages become more variable, through either settlement or the use of high-low agreements. But, in the context of our model, an increase in $x_{\mathrm{H}}-x_{\mathrm{L}}$ can either increase, decrease, or not affect the likelihood of settlement, depending on the level of $x_{\mathrm{H}}-x_{\mathrm{L}}$. The line $x_{\mathrm{H}}-x_{\mathrm{L}}=\tilde{\Delta}$ divides those cases that are optimally resolved (from the perspective of the parties) with a naked trial from those that are optimally resolved using a high-low agreement.

${ }^{35}$ The rank ordering of LC-LV and HC-HV is theoretically ambiguous, depending on the level of risk aversion of one or both parties and therefore the rate of exchange between risk and costs for each party.
} 
exogenous characteristics. Our reliance on defendants' cost data to study settlement behavior is not a major limitation. Opposing parties' litigation costs are highly correlated because they are complementary (for example, Shepherd 1999) ;6 moreover, our approach depends only on ordinal comparisons and not on absolute cost levels. We approximate outcome variance for each claim using the exogenous variation over time in the claim's reserve. The construction of these variables is described and defended in Sections 4.1 and 4.2. The central intuition behind this measurement approach is that settlement behavior is rooted in the parties' beliefs about the likely consequences of available choices (in particular, litigation costs and outcome variability); that litigants (typically represented by legal counsel with insurance litigation experience) form these expectations from the trial, arbitration, and settlement of prior disputes involving similar claims; and that, therefore, outcomes in other cases with similar characteristics can serve as proxies for these beliefs. ${ }^{37}$

\subsection{Measuring Expected Litigation Costs}

When deciding whether to propose or accept a settlement or high-low offer, a litigant must consider the likely costs of continued litigation. Although we have multiple claim-level measures of monthly litigation expenditures (including fees paid to outside counsel, internal transfers to the insurer's legal department, and fees paid to courts), we cannot use actual costs as a measure of expected costs because a claim's actual costs and how parties resolve that claim are jointly determined. ${ }^{38}$ Indeed, litigants choose whether to settle and how to manage their cases in part to avoid costs they would otherwise incur.

To estimate each claim's expected total litigation costs, therefore, we make use of the relationship between the costs of fully litigated claims (that is, those resolved through arbitration or trial) and the exogenous characteristics of those claims. We begin by estimating $C_{i}=\beta X_{i}+\varepsilon_{i}$, where $C_{i}$ represents the insurer's total actual litigation costs for a fully adjudicated claim $i$ (involving no highlow activity) and $X_{i}$ is a comprehensive set of exogenous characteristics about the dispute, including insured and claimant details, the injury or damage sus-

\footnotetext{
${ }^{36}$ Certainly the litigation costs of opposing sides will diverge over short periods of time, especially in the context of an insurer defendant (with staff attorneys and other fixed costs) and an individual plaintiff represented by a sole practitioner. Still, using $c_{\mathrm{d}}$ as a proxy for $c_{\mathrm{p}}+c_{\mathrm{d}}$ makes sense because we are concerned only with total (not monthly) expected litigation costs per claim.

${ }^{37}$ We implicitly investigate this assumption in our work by checking to see whether litigants behave in ways that are consistent with their being rational and informed about their own case and prior similar cases.

${ }^{38}$ For example, if claims that settle tend to settle early, costs will be negatively correlated with settlement, and a regression of resolution outcomes on costs would suggest that lawyers and their clients prefer to litigate expensive cases when a more likely explanation is that settlement dramatically reduces overall litigation costs.
} 
tained, the insurance policy, the location of the suit, and so on. ${ }^{39}$ We exclude any characteristic (for example, the duration of the case) that litigants might manipulate to lower their costs (including attempts to improve settlement prospects) or to raise their opponents' costs (see Gruber and Yelowitz 1999). We then take these estimated coefficients and the values of the exogenous variables for every claim in dispute and use them to generate a predicted cost for each claim had it been resolved through naked trial or arbitration. ${ }^{40}$ We view this measure as appropriate because we focus on a litigant's desire to avoid the costs of a naked trial or arbitration that would otherwise occur by default. ${ }^{41}$

Building our expected litigation costs measure using only fully litigated claims (that is, those without high-low activity) may introduce sample selection bias into our cost estimates-by assumption, cases that proceed all the way to trial or arbitration are likely to be less costly, all else equal. Fortunately, this step of our empirical strategy relies only on the ordinal rank of cases and case characteristics in terms of their relationship to actual litigation expenses. More precisely, we assume that the exogenous characteristics that make fully litigated cases more expensive also make settled cases more costly. ${ }^{42}$ Given that we rely only on preexisting claim attributes to estimate expected costs and that significant expenditures occur before settlement, we view this assumption as reasonable. Nevertheless, we produced alternative expected cost measures using all claims in dispute to estimate $\beta$ regardless of how they were resolved. This approach is less attractive, as we explain in Section 4.5, but, in any event, both measures lead to similar results. ${ }^{43}$

${ }^{39}$ More specifically, we include different subsets (four in total) of the following: a presuit estimation of liability by the insurer, the year in which the loss was reported, the year in which the lawsuit was filed, the number of individuals injured in the loss event, the types of injuries and/or losses, whether a fatality occurred, whether the claim was in the auto or general liability line of business, the state and region of the accident, the state in which the litigation occurred, the policy limit, the population density where the insured lived and where the claimant lived, the early estimates (in months 2,3 , and 4) by the insurer of its incurred losses or reserve amount on the claim, demographic data for the area in which the insured lived, and the type of claimant (individual or company).

${ }^{40}$ We use four sets of exogenous characteristics to model the actual litigation costs of fully litigated claims (see Table 5 for a description of the sets). The associated $R^{2}$ statistics (adjusting for lost degrees of freedom) range from .18 (set 1) to over .20 (set 4) as additional covariates are included.

${ }^{41}$ We also considered using "jackknife" estimates of $\beta$ in which we would run a separate regression on all adjudicated observations except one (claim $i$ ) to estimate $\beta_{-i}$ and then use $\hat{\beta}_{-i} \forall i$ to predict $\hat{C}_{i}$ so that the actual costs of claim $i$ play no role in our estimate of expected costs. We found, however, that our expected cost regression replications occasionally dropped different variables as collinear, making jackknifing impossible without eliminating some exogenous regressors. We decided against this approach. Our cost regressions involve thousands of observations, and therefore any single claim has very little influence on our estimates of $\beta$.

${ }^{42}$ For example, if litigation is more expensive in a particular state, we assume that settling in that state is at least not less expensive than it would be in other states. Likewise, if litigating a head injury case is more costly than litigating a leg injury case, we assume that settling a head injury case will, on average, entail higher costs than settling a leg injury case.

${ }^{43}$ One way to address the selection problem directly is to identify an exogenous cost shiftersome characteristic that makes certain claims more or less expensive to litigate, regardless of the stage at which the claims are resolved-and employ an instrumental variables (IV) framework. We explored many candidate instruments, including federal civil and criminal case loads and durations, 


\subsection{Measuring Expected Outcome Variance}

A litigant deciding whether to offer or accept high-low or out-of-court settlement terms must also determine whether the case is sufficiently risky or unpredictable, all else equal, to make the terms under consideration worthwhile. Certain types of claims are more likely (and are known to be more likely) than others to evolve at irregular times and in unpredictable ways. In particular, for each category of disputed claim, it may be more or less common for new information about the claim, the evidence relating to the claim, the opposing party, or the opposing party's strategy to emerge in ways that significantly alter the litigation landscape and therefore the likely outcome of any adjudication. ${ }^{44}$

Our data include each claim's monthly reserve amount (or incurred loss) the then-current, but conservative, best guess of the claim's litigation value. The reserve is a claim-specific amount that an insurer allocates to cover its potential obligations under an insurance contract. ${ }^{45}$ All insurers are required by state law to set reserve amounts. ${ }^{46}$ In theory, when setting the reserve, the insurer balances legal and economic factors: ensuring sufficient liquidity to cover any required payout on a claim while at the same time not forgoing more profitable investments for its capital any more than is necessary. ${ }^{47}$ Importantly, the insurer that made its data available to us reports that it evaluates its claim handlers' abilities in part by the accuracy of their reserve determinations.

Over the course of any dispute, the insurer adjusts the reserve amount over time to account for new information about the underlying loss event or the litigation. A claim's reserve amount can change dramatically month to month as newly relevant information comes to light. We use the variance of the reserve

state civil and criminal per capita case loads, state-specific cost averages, state fixed effects, and an indicator for whether the case was being litigated in a state other than the one in which the loss occurred, but our first-stage results were too weak to pursue an IV strategy. Variation in litigation expenses appears to be driven much more by claimant-, insured-, or claim-specific differences than by exogenous cost shocks or shifters such as a change in state law or statewide patterns.

${ }^{44}$ For example, in the context of our model, if $x_{\mathrm{H}}-x_{\mathrm{L}}$ is large, then even small changes in $\pi$ (the likelihood that the plaintiff prevails in court) could lead to large changes in the expected payout.

${ }^{45}$ Grace (1990) finds evidence that deviations between the reserves and future losses are not random and may be a mechanism for smoothing income. Other work shows that financially secure insurers tend to be more conservative in setting reserves than their less-secure counterparts (Petroni 1992; Gaver and Paterson 2007; Petroni et al. 2000). These papers do not look at claim-level reserves, as we do here, however. Black et al. (2008) detect no relationship between defense costs and reserves in claim-level medical malpractice data, which leads the authors to question insurers' rationality, despite finding such a relationship in other claim types.

46 "All states impose reserve requirements on insurers to provide protection to policyholders, assuring that assets will be available to pay claims" (McGuire 1996, p. 38). Salzmann (1984) discusses common methods for estimating reserves.

${ }^{47}$ Because a reserve is an estimate of a filed claim's likely value and is determined internally for record keeping and regulatory compliance, there is no strategic reason-at least with respect to any individual claim - for the insurer or its employees to manipulate the valuation process. We asked the insurer's officers whether there was a more precise meaning to the best-guess description and learned only that the reserve is the expected value, viewed conservatively. We interpret this to mean that the reserve is set at some point between the 50th and 60th percentile of the insurer's estimated distribution of likely damages. 
amount over the course of the claim's life, conditional on the claim's duration, as a proxy for expected claim volatility. ${ }^{48}$ In adopting this strategy, we continue to assume that litigants are knowledgeable about their own cases and other cases with similar characteristics and are therefore able to use exogenous case characteristics to ascertain the likely variance of a claim's monthly reserve. ${ }^{49}$

Finally, we note that, although variance in the reserve amount can account for riskiness because of unanticipated information shocks during litigation, our measure does not proxy for any predictable randomness in judge or jury verdicts. ${ }^{50}$ Even a case that is expected to develop predictably between when a claim is filed and when the presentation of evidence ends and the fact finder's deliberations begin-that is, a claim that in theory should have predictably stable reserves throughout the course of litigation-may still be considered very risky from beginning to end if the fact finder involved is known to behave unpredictably when faced with the type of claim at issue. Because these two types of uncertainty are likely to be independent of each other, however, and at a minimum because there is no reason to believe that they are negatively correlated, failing to capture latent fact finder unpredictability is unlikely to confound our empirical results.

\subsection{Defining Claim Resolution Outcomes}

The simple model presented in Section 2 implies a clear categorization of how claims move toward resolution: parties either proceed directly to naked adjudication, agree to settle out of court, or enter into a high-low agreement before they adjudicate their dispute. In reality, however, litigants may initiate negoti-

\footnotetext{
${ }^{48}$ This measure also has a clear link to the value $x_{\mathrm{H}}-x_{\mathrm{L}}$ from our model. Suppose that a reserve amount set aside for a claim at any point in time $t$ is the estimated expected value of the claim if the dispute is resolved by a court. Denote this reserve by $R_{t}$. Suppose further that $x_{\mathrm{H}}-x_{\mathrm{L}}$ is certain and known to both parties and that $\rho=\left(\rho_{1}, \rho_{2}, \ldots, \rho_{T}\right)$ is the time series representing the evolving probability of high damages. Then, at time $t$ the reserves $R_{t}$ are a linear function of $\rho_{t}$ given by $R_{t}=\rho_{t} x_{\mathrm{H}}+\left(1-\rho_{t}\right) x_{\mathrm{L}}=x_{\mathrm{L}}+\rho_{t}\left(x_{\mathrm{H}}-x_{\mathrm{L}}\right)$. Therefore, if $V$ denotes the volatility of $\rho$, then the volatility of the time series of reserves is given by $V\left(x_{\mathrm{H}}-x_{\mathrm{L}}\right)$ and the volatility of the reserves process is a linear function of $x_{\mathrm{H}}-x_{\mathrm{L}}$. Note that related measures of volatility are possible using the reserve information, including the total number of changes to the reserve amount, the difference between the first reserve amount and the last reserve amount, and so on.

${ }^{49}$ We also constructed a number of candidate volatility instruments. For example, we considered tort reforms designed to limit excessive verdicts (for example, laws that cap damages and joint-andseveral liability reforms), but the first stage was too weak. We also examined changes to offer-ofjudgment rules, because a law that shifts attorneys' fees will increase outcome variance, but there was too little within-state legal variation for this to be a productive strategy (only one or two states made significant reforms during our sample period).

${ }^{50}$ If reserves are truly set at the 55th or 60 th percentile of a symmetric damages distribution (or, really, anything strictly above the median), one could also measure a claim's expected outcome volatility by using a quantile regression framework and exogenous claim characteristics to estimate the 90th and the 50th percentiles of the reserve amount distribution in, say, the fifth month of every claim's life. The larger the ratio of the 90th to the 50th percentile estimates, the greater the expected outcome variance should be. One advantage of this approach is that claim types that have constant reserves but are nevertheless risky because of fact finder unpredictability may have greater spreads in their fifth-month reserves, all else equal. The same approach could be used to predict the spread in the final loss paid amount, although this method may suffer from sample selection bias.
} 
ations or renegotiate their agreements at any time-for example, when new facts about the litigation become apparent or litigants' preferences or resources change. In our data, for instance, litigants regularly revisit their high-low agreements, often replacing them with out-of-court settlements and avoiding trial altogether. ${ }^{51}$ This potential for renegotiation of course complicates any attempt to categorize claims by how they were resolved. ${ }^{52}$

In our empirical work, we categorize claims as involving a high-low discussion or agreement if the parties ever enter into a high-low discussion or agreement during the dispute-even if the claim in question is eventually resolved by outof-court settlement or naked adjudication. We take this approach because we are fundamentally interested in the conditions that lead litigants to consider entering into a high-low agreement, even one that may ultimately be renegotiated and may therefore be temporary. After all, renegotiating from a high-low agreement to full settlement would most likely occur as the result of a cost shock that makes continuing the litigation too expensive, ${ }^{53}$ and once a high-low agreement is in place, the game changes-both parties must agree to any superseding contract.

The consideration, discussion, and negotiation of a potential high-low agreement between the parties are each separately meaningful and important outcomes in their own right. Discussions often do not graduate to agreements because of transaction costs or chance factors, parties who discuss a high-low agreement are more interested in such an arrangement than those who do not, and a highlow discussion may proxy for an agreement that was not included in the litigation notes we examined. High-low discussions also have the advantage of being far more numerous than actual agreements, which allows for more reliable statistical testing. ${ }^{54}$

\footnotetext{
${ }^{51}$ Theoretically, if both litigants were to become more optimistic ex post, they might prefer to unwind a settlement or void a high-low agreement and pursue a full-blown trial instead, but we see no evidence of this behavior in our data, and it strikes us as likely to be extremely rare.

${ }^{52}$ This two-stage settlement process (that is, first a high-low agreement, then full settlement) may have a behavioral explanation as well. Instead of being a rational response to new information about litigation costs, settlement might follow a high-low agreement because litigants bound by a highlow agreement view their range of options differently than they did prior to concluding the highlow arrangement, a change in perspective that the parties may not have anticipated. For example, after agreeing to a high-low contract to guarantee a minimum recovery, a plaintiff may come to believe that, given a huge damages award is no longer possible, full settlement is simply more attractive than she had predicted it would seem before she consented to the high-low agreement.

${ }^{53}$ On the other hand, temporary high-low agreements may exist, for instance, because artificial time constraints (imposed by settlement conferences, for example) make it impossible to negotiate full settlements all at once. A high-low agreement may be easier to obtain (although our model actually considers the opposite possibility explicitly-that high-low agreements may be relatively costly to negotiate) and may be viewed optimistically as temporary but valuable protection against extreme trial outcomes.

${ }^{54}$ In unreported work, we also consider a narrower definition, defining a claim as involving highlow activity only if the litigation was resolved at trial or in arbitration with that agreement still in place.
} 


\subsection{Predicting High-Low Discussions and Agreements}

Our empirical strategy identifies the claim-specific factors associated with each of three mutually exclusive claim resolution outcomes: naked trials or arbitrations, high-low discussions or agreements, and out-of-court settlements. Because these categories are not meaningfully ordered and because other assumptions underlying the approach are likely to be satisfied, we adopt a multinomial logit framework, which allows us to calculate the probability of a particular outcome relative to a baseline category. More precisely, we estimate

$$
p\left(y_{i}=j\right)=\frac{\exp \left(\boldsymbol{x}_{i j}^{\prime} \hat{\boldsymbol{\gamma}}_{j}\right)}{\sum_{k} \exp \left(\boldsymbol{x}_{i k}^{\prime} \hat{\boldsymbol{\gamma}}_{k}\right)} .
$$

The matrix $\boldsymbol{x}_{i j}$ denotes claim $i$ s characteristics, which are associated with each of the $J$ alternative dispute outcomes, and $\hat{\gamma}$ is the $K \times 1$ vector of estimated coefficients that characterizes the relationship between expected litigation costs and expected payout variance to the claim resolution outcome. Because a fullblown trial occurs absent some agreement, resolution through naked trial or arbitration serves as our baseline category. ${ }^{55}$

To keep our analysis simple, we incorporate expected litigation costs and expected volatility into our primary regressions as indicator variables $\left(\boldsymbol{x}_{i j}\right)$ that we construct in the following way: ${ }^{56}$ Using all disputed claims, we calculate the median expected litigation costs and the median expected outcome volatility. We then categorize claims as above or below the median in each category. Finally, we use the interactions of these two measures to define four groups: HC-HV, LC-HV, HC-LV, and LC-LV. For the behavior in our data to be consistent with our model's predictions, claims with below-median expected litigation costs and above-median outcome variance (LC-HV) should be relatively more likely to involve a high-low discussion or agreement. Although parsimonious, our empirical approach intuitively examines our theory and generates results that are straightforward in their interpretation.

\footnotetext{
${ }^{55}$ This modeling approach generated a host of thorny technical issues when we attempted to use instrumental variables methods to remove any selection effects. Estimating a multinomial logit model with endogenous regressors is, to say the least, nontrivial. We employed the control function approach described in Terza, Basu, and Rathouz (2008), although this approach is not fully satisfactory. See Imbens and Wooldridge (2007, p. 17): "Allowing endogenous explanatory variables [EEVs] in multinomial response models is notoriously difficult, even for continuous endogenous variables. . . . First, multinomial probit [MNP], which mixes well [with] a reduced form normality assumption for $D\left(y_{2} \mid \mathbf{z}\right)$, is still computationally difficult for even a moderate number of choices. Apparently, no one has undertaken a systematic treatment of MNP with EEVs. . . . The multinomial logit $[\mathrm{MNL}]$. . . is much simpler computationally with lots of alternatives. Unfortunately, the normal distribution does not mix well with the extreme value distribution, and so, if we begin with a structural MNL model . . . . , the [control function approach's] estimating equations are difficult to obtain, and MLE is very difficult, too, even if we assume a normal distribution in the reduced form $[\mathrm{s}]$.”

${ }^{56}$ Our framework makes use of generated regressors, and, as a consequence, the usual approach to calculating standard errors results in biased estimates (Murphy and Topel 1985). To remedy this concern, we report standard errors calculated by bootstrapping.
} 
Table 5

Likelihood of High-Low Discussion or Agreement and Full Settlement Relative to Trial or Arbitration

\begin{tabular}{|c|c|c|c|c|}
\hline & (1) & (2) & (3) & (4) \\
\hline \multicolumn{5}{|c|}{ High-low discussion: } \\
\hline \multirow{3}{*}{ HC-HV } & 4.255 & 4.140 & 4.657 & 5.293 \\
\hline & $(.736)$ & $(.725)$ & $(.964)$ & $(1.112)$ \\
\hline & {$[.00]$} & {$[.00]$} & {$[.00]$} & {$[.00]$} \\
\hline \multirow[t]{3}{*}{ LC-HV } & 5.198 & 5.712 & 7.097 & 8.486 \\
\hline & $(1.180)$ & $(1.228)$ & $(1.689)$ & $(2.215)$ \\
\hline & {$[.01]$} & {$[.00]$} & {$[.00]$} & {$[.01]$} \\
\hline \multirow[t]{3}{*}{ LC-LV } & 1.281 & 1.375 & 1.684 & 1.551 \\
\hline & $(.315)$ & $(.338)$ & $(.438)$ & $(.431)$ \\
\hline & {$[.39]$} & {$[.29]$} & {$[.15]$} & {$[.23]$} \\
\hline \multicolumn{5}{|l|}{ Settlement: } \\
\hline \multirow[t]{3}{*}{ HC-HV } & 1.103 & 1.131 & 1.045 & 1.062 \\
\hline & $(.074)$ & $(.076)$ & $(.080)$ & $(.101)$ \\
\hline & {$[.19]$} & {$[.11]$} & {$[.59]$} & {$[.55]$} \\
\hline \multirow[t]{3}{*}{ LC-HV } & 1.012 & 1.178 & 1.182 & 1.205 \\
\hline & $(.103)$ & $(.121)$ & $(.151)$ & $(.151)$ \\
\hline & {$[.91]$} & {$[.17]$} & {$[.26]$} & {$[.20]$} \\
\hline \multirow[t]{3}{*}{ LC-LV } & .757 & .862 & .818 & .804 \\
\hline & $(.070)$ & $(.081)$ & $(.094)$ & $(.096)$ \\
\hline & {$[.01]$} & {$[.12]$} & {$[.08]$} & {$[.07]$} \\
\hline \multicolumn{5}{|c|}{ Expected litigation costs: ${ }^{a}$} \\
\hline Set 1 & Yes & Yes & Yes & Yes \\
\hline Set 2 & & Yes & Yes & Yes \\
\hline Set 3 & & & Yes & Yes \\
\hline Set 4 & & & & Yes \\
\hline$N$ & 45,379 & 44,000 & 36,113 & 32,317 \\
\hline
\end{tabular}

Note. Litigation costs are predicted using litigated cases. Estimates are reported as relative risk ratios. The outcome variable captures whether a claim ever involved a high-low discussion or agreement and, if not, whether it settled out of court or was resolved through trial or arbitration (excluded category). The independent variables are indicators for the interaction between an indicator for whether the claim had above- or below-median expected litigation costs and an indicator for whether the claim had above- or below-median expected outcome variance. Therefore, HC-HV is one for claims with above-median $(\mathrm{H})$ expected litigation costs $(\mathrm{C})$ and above-median $(\mathrm{H})$ expected outcome variance $(\mathrm{V})$ and zero otherwise, and so on. Bootstrapped standard errors are in parentheses, and p-values are in brackets.

${ }^{a}$ Set 1 includes state of litigation fixed effects, accident region fixed effects, fixed effects for the insurance company's estimate of percentage of liability, year effects for when the accident was reported, fixed effects for the number of persons injured in the event, fixed effects for type of injury or damage, a fatality indicator, and an indicator for whether the line of business was automobile liability or general liability. Set 2 adds state of accident fixed effects, the insurance policy claim limit, the population density of the insured's geographic area, and the insurance company's estimates of incurred loss in months 3, 4, and 5 after the filing of the claim. Set 3 adds variables about the area where the insured lives, the type of plaintiff (corporate or individual), and the population density of the plaintiff's geographic area. Set 4 adds an indicator for the year in which the suit was filed.

\subsection{Empirical Results}

In Table 5, we present evidence that high-low discussions and agreements are much more likely to occur when a claim's expected litigation costs are relatively low and its expected outcome volatility is relatively high, a finding consistent with the predictions of our model. With HC-LV claims serving as our omitted category, the top half of the table reports the relative difference in the likelihood 
that litigants engage in high-low discussions and agreements (versus adjudication with no such discussion) between a case that has high costs and low volatility and cases from the other three groups. To make the interpretation of these estimates more concrete, the risk ratios for $\mathrm{HC}-\mathrm{HV}$ claims, for example, imply that moving from below-median variance to above-median variance when litigation costs are expected to be high (in other words, replacing HC-LV claims with HC-HV claims) increases the odds of a high-low discussion or agreement on average by more than 4 times, and possibly more than 5 times, depending on how the expected litigation costs are calculated. ${ }^{57}$ Although the overall base likelihood of a high-low discussion occurring in these cases is fairly small, this difference is nevertheless dramatic and substantively important.

With respect to LC-LV claims in the top half of Table 5, our data show no statistically significant difference in the likelihood of high-low activity between claims with above-median expected costs and claims with below-median costs when outcome volatility is expected to be low, although the point estimate in column 4 indicates that a discussion is approximately 50 percent more likely. This result, too, makes sense in the context of our model because shifting from a naked trial to a high-low agreement does not, in our model, reduce litigation costs. Only fully settling a case has that consequence. Therefore, the preferred choice between a high-low agreement and full adjudication should not differ across claims if only the expected cost of litigation varies, unless high-low agreements offer some means of lowering costs. The point estimate for LC-LV claims hints at that possibility, and we explore the idea explicitly in Section 5 by modeling high-low agreements as commitment devices to restrain wasteful expenditures.

Finally, we assess the difference between HC-LV claims and LC-HV claims in the relative likelihood of generating a high-low discussion or agreement (versus proceeding to naked adjudication without a discussion). In line with our model, we find that lower expected costs and higher expected outcome volatility increase the odds of a high-low discussion between five- and ninefold. Taken together, the results for $\mathrm{HC}-\mathrm{HV}$ and $\mathrm{LC}-\mathrm{LV}$ claims point to claim volatility as the likely source for this increase: the differences in the HC-HV and LC-HV relative risk ratios are not statistically significant, and the numbers for LC-LV claims show that, as between naked adjudication with and without high-low activity, costs may be irrelevant. Still, one could hypothesize that the differences in the point estimates between the HC-HV and LC-HV claims imply some interaction between costs and volatility, with high litigation costs magnifying the role any difference in outcome volatility may play.

With respect to settlement, our model also performs well, although not as

\footnotetext{
${ }^{57}$ In Table 5, we use only fully litigated cases (without high-low agreements) to calculate expected litigation costs. Each column uses a different set of exogenous variables (fixed at the time the claim is filed) to predict expected litigation costs. We show all four sets of results because adding variables to our prediction regressions results in the loss of observations, including cases with high-low agreements, but improves the overall performance of these regressions in accounting for variation in litigation costs.
} 
well as it does in explaining high-low discussions and without the same level of statistical precision. In the bottom half of Table 5, with settlement as the outcome, we expect the relative risk ratios on $\mathrm{HC}-\mathrm{HV}$ to be larger than they are on LC$\mathrm{HV}$, whereas with high-low activity as the outcome we expect the opposite relationship. We find this to be true only in column 1 . Nevertheless, the estimates in all columns are similar to each other and statistically indistinguishable from the value of 1 . Only the coefficients on LC-LV regularly approach statistical significance: LC-LV claims are only 75-85 percent as likely as HC-LV claims to settle (as opposed to going to trial or arbitration without the parties discussing the possibility of a high-low agreement), a result that is fully consistent with our model's predictions.

\subsection{Robustness Checks}

We perform a number of specifications and other checks within the context of our multinomial framework and find that our results are robust. Section 4.5 included high-low discussions and agreements (rather than just high-low agreements) because, in our view, high-low negotiations are arguably just as relevant in thinking about settlement behavior and are more numerous $(n=935)$, which reduces the likelihood of any bias resulting from high-low agreements being relatively rare events (see King and Zeng 2001). ${ }^{58}$ Nevertheless, claims with low expected costs and high expected outcome volatility should generate relatively more agreements, not just more discussions. In fact, the empirical relationship with respect to agreements may be stronger if we happen to identify agreements in our data more accurately than we do claims involving discussions or if discussions occur before parties have had the ability to conduct a full investigation into the essential details of a claim (which leads to greater uncertainty about the claim's likely litigation costs and volatility).

The relationship of expected litigation costs and claim volatility to the likelihood of actual high-low agreements $(n=246)$ is shown in Table 6. Our findings again align with our model's predictions about claim resolution behavior. The estimates in Table 6 are slightly less precise than the ones presented in Table 5. Nevertheless, we find statistically significant coefficients on LC-HV and even larger relative risk ratio magnitudes. We also repeated the analysis while restricting attention to only those claims resolved through trial or arbitration with

\footnotetext{
${ }^{58}$ High-low discussions are not especially rare events in our sample. More than 2 percent of all of the disputed claims in our data involved high-low discussions. More important, even if our estimates were to suffer from rare-events bias, theoretical and Monte Carlo work by King and Zeng (2001) shows that logit analyses tend to underestimate the probability of rare events (that is, highlow discussions or high-low agreements), a bias that should run against the results we find. Moreover, the extent of possible bias when the total number of observations (disputed claims) is almost 50,000, as it is here, is unlikely to explain the large coefficients we find on LC-HV. Alternative approaches to building our sample, such as endogenous stratified sampling, would more likely than not simply increase the magnitude of our estimates.
} 
Table 6

Likelihood of High-Low Agreement and Full Settlement Relative to Trial or Arbitration

\begin{tabular}{|c|c|c|c|c|}
\hline & (1) & (2) & (3) & (4) \\
\hline \multicolumn{5}{|c|}{ High-low agreement: } \\
\hline \multirow{3}{*}{ HC-HV } & 4.167 & 4.152 & 5.053 & 3.679 \\
\hline & $(1.404)$ & $(1.383)$ & $(1.592)$ & $(1.188)$ \\
\hline & {$[.05]$} & {$[.05]$} & {$[.03]$} & {$[.05]$} \\
\hline \multirow[t]{3}{*}{ LC-HV } & 6.977 & 8.179 & 10.191 & 8.759 \\
\hline & $(2.505)$ & $(2.707)$ & $(3.414)$ & $(3.048)$ \\
\hline & {$[.04]$} & {$[.02]$} & {$[.02]$} & {$[.03]$} \\
\hline \multirow[t]{3}{*}{ LC-LV } & 1.483 & 1.629 & 1.902 & 1.341 \\
\hline & $(.612)$ & $(.603)$ & $(.708)$ & $(.536)$ \\
\hline & {$[.45]$} & [.32] & [.23] & {$[.54]$} \\
\hline \multicolumn{5}{|l|}{ Settlement: } \\
\hline \multirow[t]{3}{*}{ HC-HV } & 1.082 & 1.113 & 1.030 & 1.043 \\
\hline & $(.071)$ & $(.073)$ & $(.077)$ & $(.098)$ \\
\hline & {$[.28]$} & {$[.15]$} & {$[.71]$} & {$[.67]$} \\
\hline \multirow[t]{3}{*}{ LC-HV } & 1.000 & 1.156 & 1.166 & 1.196 \\
\hline & $(.100)$ & $(.117)$ & $(.149)$ & $(.150)$ \\
\hline & {$[1.00]$} & {$[.21]$} & [.29] & {$[.22]$} \\
\hline \multirow[t]{3}{*}{ LC-LV } & .761 & .866 & .820 & .804 \\
\hline & $(.071)$ & $(.082)$ & $(.094)$ & $(.096)$ \\
\hline & [.01] & [.13] & [.09] & {$[.07]$} \\
\hline \multicolumn{5}{|c|}{ Expected litigation costs: ${ }^{a}$} \\
\hline Set 1 & Yes & Yes & Yes & Yes \\
\hline Set 2 & & Yes & Yes & Yes \\
\hline Set 3 & & & Yes & Yes \\
\hline Set 4 & & & & Yes \\
\hline$N$ & 45,375 & 43,996 & 36,112 & 32,317 \\
\hline
\end{tabular}

Note. Litigation costs are predicted using litigated cases. Estimates are reported as relative risk ratios. The outcome variable captures whether a claim ever involved a high-low agreement and, if not, whether it settled out of court or was resolved through trial or arbitration (excluded category). The independent variables are indicators for the interaction between an indicator for whether the claim had above- or belowmedian expected litigation costs and an indicator for whether the claim had above- or below-median expected outcome variance. Therefore, $\mathrm{HC}-\mathrm{HV}$ is one for claims with above-median $(\mathrm{H})$ expected litigation costs $(\mathrm{C})$ and above-median $(\mathrm{H})$ expected outcome variance $(\mathrm{V})$ and zero otherwise, and so on. Bootstrapped standard errors are in parentheses, and $p$-values are in brackets.

${ }^{a}$ Set 1 includes state of litigation fixed effects, accident region fixed effects, fixed effects for the insurance company's estimate of percentage of liability, year effects for when the accident was reported, fixed effects for the number of persons injured in the event, fixed effects for type of injury or damage, a fatality indicator, and an indicator for whether the line of business was automobile liability or general liability. Set 2 adds state of accident fixed effects, the insurance policy claim limit, the population density of the insured's geographic area, and the insurance company's estimates of incurred loss in months 3, 4, and 5 after the filing of the claim. Set 3 adds variables about the area where the insured lives, the type of plaintiff (corporate or individual), and the population density of the plaintiff's geographic area. Set 4 adds an indicator for the year in which the suit was filed.

high-low agreements in place $(n=99){ }^{59}$ Finally, to insure against the possibility that selection bias in our calculation of expected litigation costs might account for our findings (see Section 4.1), we also reconstructed our expected litigation

\footnotetext{
${ }^{59}$ We wind up with relatively few high-low claims to study with this approach, and the standard errors that we estimate via bootstrapping are too large for us to say anything definitive. We view these results as consistent with and weakly corroborative of the evidence we present.
} 
cost covariates using the actual costs of all claims in dispute (rather than just fully litigated claims). ${ }^{60}$ The results of these last two exercises are similar to those reported in Tables 5 and 6 , and the magnitudes and patterns of the high-low estimates remain consistent with our model's predictions.

One concern with our empirical framework is the loss of information that accompanies our making discrete the initially continuous litigation cost and outcome variance measures into dichotomous variables to create just four types of claims to compare. We find this approach attractive for two reasons. First, without loss of generality, these simplifying steps make the presentation of our results straightforward and the interpretation intuitive. More important (and yet less obvious), the nature of the empirical problem that we face actually precludes any simple use of continuous measures of expected costs and outcome variance as independent variables in a regression framework.

In particular, our work hinges crucially on the facts that we have three unordered outcomes (settlement, high-low activity, naked adjudication) and complicated predictions about how costs and variance (and, in particular, their interaction) influence the relative likelihood of these outcomes. High-low activity should be more likely, according to our model and all else equal, when expected litigation costs are low and when expected outcome variance is high (see Figure 1). With three unordered outcomes, an interaction term is necessary, but after normalizing to make any results interpretable, a cost-variance interaction term can take on the same value when expected litigation costs are low and outcome variance is high or when costs are high and variance is low, which frustrates alternative strategies to hypothesis testing.

To test the robustness of our results and to make better use of the information contained in our data, we take the simple nonparametric approach of mapping the likelihood of particular outcomes onto a space defined by expected litigation costs and outcome variance quantiles and oriented to match the layout of Figure 1. In Figures 2-7, the more common a particular outcome (for example, a highlow discussion, a high-low agreement, or adjudication under a high-low agreement) in a quantile cell (relative to that same outcome in other cells), the darker its shading. Figures 2 and 4 visually reproduce the key results of Tables 5 and 6 , respectively. Figure 6 shows the relative likelihood of high-low adjudication. Figures 3, 5, and 7 confirm the basic picture of Figures 2, 4, and 6 (and our

\footnotetext{
${ }^{60}$ The high-low results of this test (reported in Table A2) show relative risk ratios that are similar to those in Tables 5 and 6, but our findings on the relative likelihood of settlement (versus naked adjudication) differ. In particular, an HC-HV claim appears to be 15-20 percent more likely to settle than an HC-LV claim, a finding that is marginally statistically significant and at odds with the insignificant results of Tables 5 and 6 . Of course, this finding might stem from using all disputed claims (even those that settle) to predict litigation costs. Because settlement avoids, by design, many of the costs of fully litigated cases, including cost information from settled claims is likely to generate a spurious correlation between high litigation costs and the decision to adjudicate a claim. But this difference with Tables 5 and 6 is also entirely consistent with our model, which includes negotiation and drafting costs for high-low agreements $\left(k_{\mathrm{p}}\right.$ and $\left.k_{\mathrm{d}}\right)$ - that is, in our model, a case with higher than median volatility can be more likely to settle than cases with lower costs and lower volatility.
} 


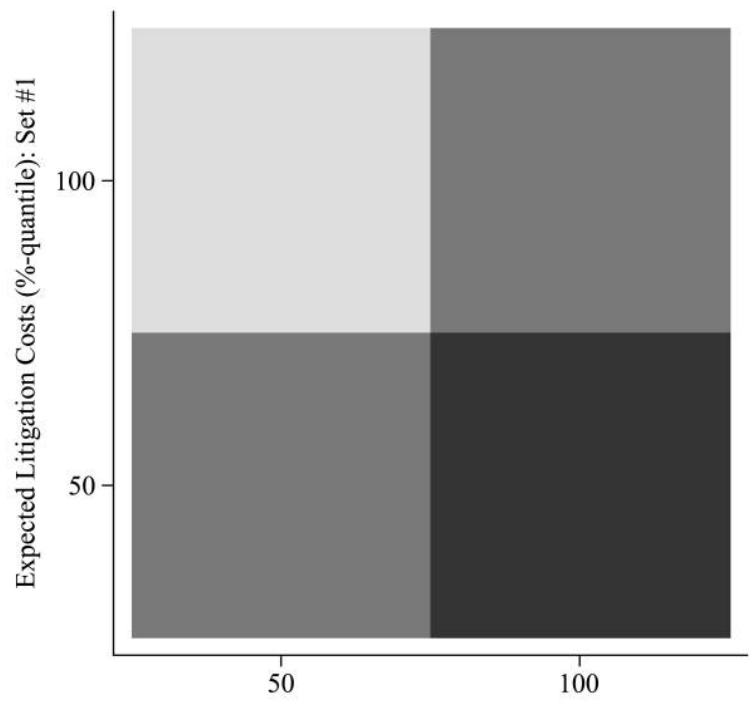

Outcome Variance (\%-quantile)

Figure 2. Density of high-low discussions: $2 \times 2$ litigation cost-outcome variance space

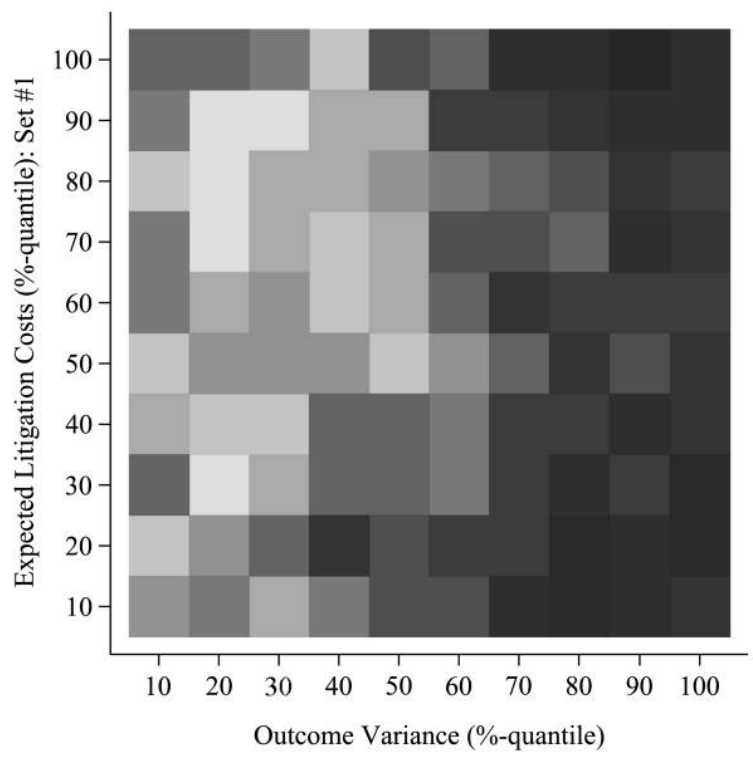

Figure 3. Density of high-low discussions: $10 \times 10$ litigation cost-outcome variance space 


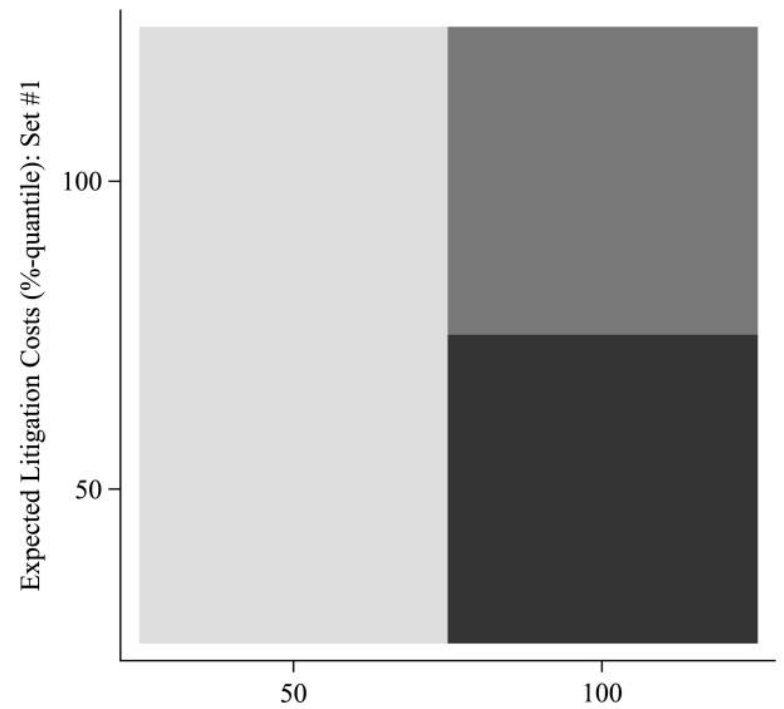

Outcome Variance (\%-quantile)

Figure 4. Density of high-low agreements: $2 \times 2$ litigation cost-outcome variance space

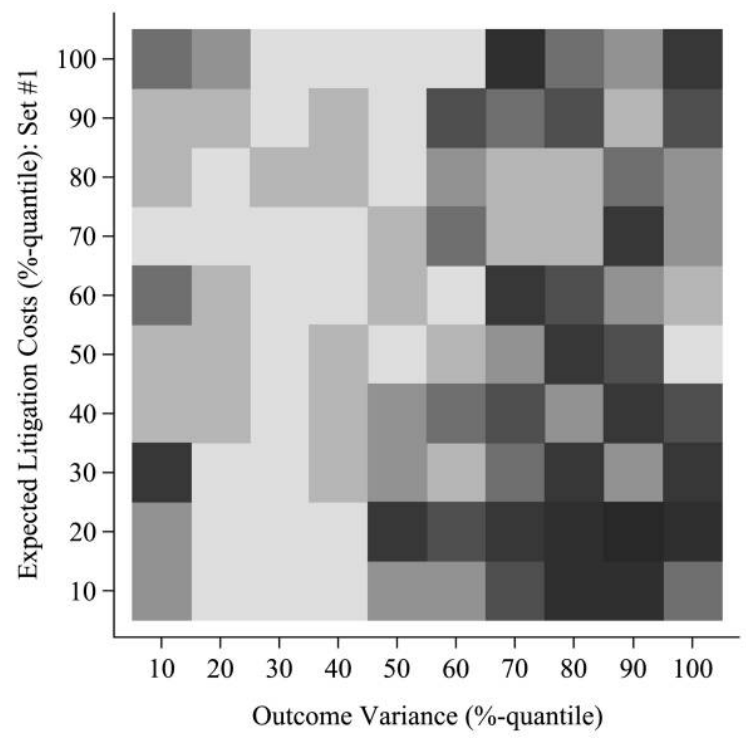

Figure 5. Density of high-low agreements: $10 \times 10$ litigation cost-outcome variance space 


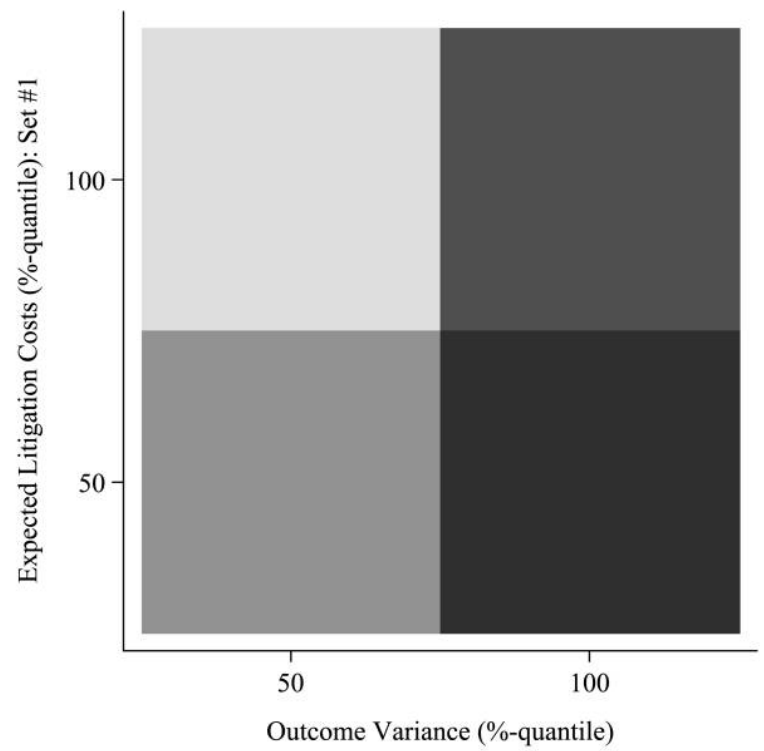

Figure 6. Density of high-low adjudications: $2 \times 2$ litigation cost-outcome variance space

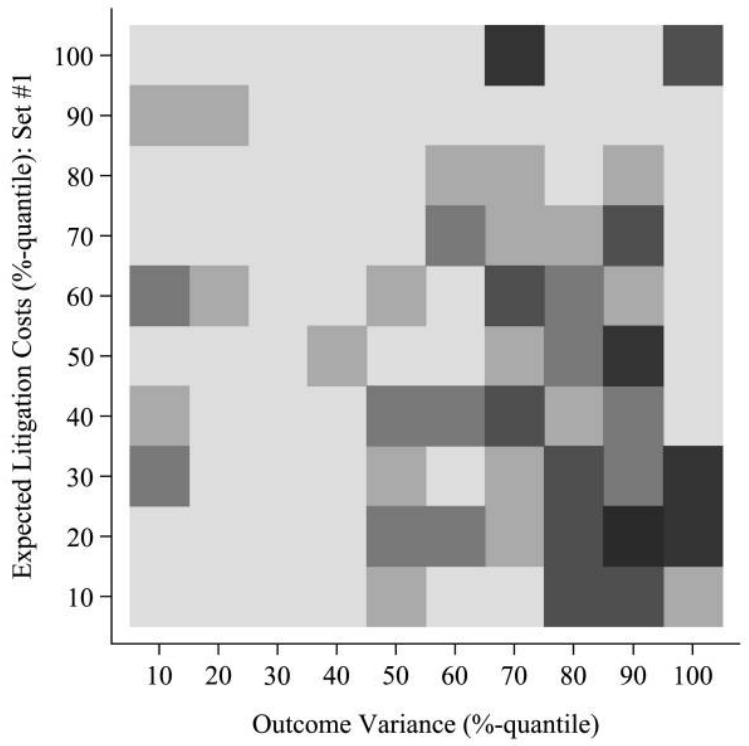

Figure 7. Density of high-low adjudications: $10 \times 10$ litigation cost-outcome variance space 
regression work) by cutting the data more finely, taking advantage of the variation in the independent variables in a natural way. ${ }^{61}$

Finally, to further evaluate the soundness of our empirical approach, we estimated three simple, straightforward dichotomous-choice logit models (one for each outcome) with expected litigation costs and outcome variance entering separately as continuous independent variables. ${ }^{62}$ This empirical strategy departs significantly from our motivating model's structure and underlying assumptions, but it allows us to investigate the consequences of incorporating continuous measures of expected litigation cost and outcome variance and relaxing the independence-of-irrelevant-alternatives assumption that accompanies the use of the multinomial logit in equation (3). ${ }^{63}$ The results of these exercises are consistent with the preceding analysis.

\section{High-Low Agreements as a Mechanism to Limit Rent Seeking}

The framework developed in Section 2 treated litigation costs as if they were set exogenously. In practice, however, litigation costs are determined endogenously by the choices the parties make: plaintiffs and defendants choose how much to invest in litigating their cases in light of the risks and potential rewards at trial. In many settings, the investment incentives of a plaintiff and a defendant may be excessive in the sense that both parties would be better off if they could each agree to spend less. By restricting the potential award to a narrower range, high-low agreements may, in theory, serve as a commitment device to limit rentseeking activities and reduce litigation costs.

To illustrate, consider a rent-seeking contest between two risk-neutral parties in which greater litigation expenditures improve a litigant's odds of prevailing at trial: ${ }^{64}$ the court awards high damages $\left(x_{\mathrm{H}}\right)$ with probability $\pi+\beta\left(e_{\mathrm{p}}^{1 / 2}-\right.$ $\left.e_{\mathrm{d}}^{1 / 2}\right)$ and low damages $\left(x_{\mathrm{L}}\right)$ with probability $1-\pi-\beta\left(e_{\mathrm{p}}^{1 / 2}-e_{\mathrm{d}}^{1 / 2}\right)$, where $\pi$ is exogenously given, $e_{\mathrm{p}}$ and $e_{\mathrm{d}}$ represent each side's litigation expenditures, and $\beta$ captures the trial outcome's sensitivity to those expenditures by the parties.

Absent any agreement, the Nash equilibrium spending levels increase mon-

\footnotetext{
${ }^{61}$ To clarify, Figures 2-7 report the relative density of cases at the intersection of each expected litigation cost quantile and each outcome variance quantile. Expected litigation costs were predicted using litigated cases; see the text or the notes to Tables 5 or 6 for further explanation.

${ }^{62}$ In particular, we separately regressed whether a claim settled on expected litigation costs and outcome variance (treating all trial and arbitration outcomes as identical), whether the parties discussed or entered into a high-low agreement on expected litigation costs and outcome variance (grouping settlement and naked trials and arbitrations together), and whether the parties discussed or entered into a high-low agreement conditional on the claim not fully settling (nesting the choices by assuming that the parties first decide whether to settle and then whether to enter into a highlow agreement).

${ }^{63}$ Importantly, the independence-of-irrelevant-alternatives assumption appears reasonably likely to hold in this context. Not one of the relevant outcomes-full settlement, a high-low agreement, or naked adjudication-is anywhere close to a perfect substitute for one of the others.

${ }^{64}$ See, for example, Tullock (1980), Dixit (1987), and Siegel (2009) for related work on contest models.
} 
otonically in $x_{\mathrm{H}}-x_{\mathrm{L}}$, the spread of possible trial outcomes. ${ }^{65}$ In particular,

$$
e_{\mathrm{p}}=e_{\mathrm{d}}=\frac{\beta^{2}\left(x_{\mathrm{H}}-x_{\mathrm{L}}\right)^{2}}{4} \text {. }
$$

By contractually restricting the spread of possible trial outcomes, however, litigants can commit themselves to invest less in the litigation-indeed, to invest the jointly optimal level. In particular, when $\pi_{\mathrm{p}}>\pi_{\mathrm{d}}$, the set of Pareto-optimal contracts will satisfy the following equation: ${ }^{66}$

$$
s_{\mathrm{L}}=s_{\mathrm{H}}-\frac{\left(\pi_{\mathrm{p}}-\pi_{\mathrm{d}}\right)}{\beta^{2}} .
$$

Intuitively, when litigants are mutually optimistic $\left(\pi_{\mathrm{p}}>\pi_{\mathrm{d}}\right)$, they jointly benefit from the speculation value of trial, but they also want to avoid squandering that joint benefit by making offsetting investments (wasteful rent seeking) that are nonetheless privately optimal in a noncooperative setting. The contract trades off these two objectives. Both parties would rather maximize their joint benefit by agreeing to reduce their litigation expenditure levels, and assuming that parties cannot verify spending and so cannot contract on that behavior directly, a highlow agreement can accomplish this same goal indirectly by reducing the sensitivity of the final outcome to these investments. Note that the high-low spread, $s_{\mathrm{H}}-s_{\mathrm{L}}$, is smaller when $\beta$ is larger, which means that when outcomes are more sensitive to expenditures, litigants have an even greater incentive to constrain their costs through a tighter high-low spread.

Some of the predictions of this rent-seeking model are, at a superficial level, similar to those of our original model: parties will tend to adopt high-low contracts when the spread $x_{\mathrm{H}}-x_{\mathrm{L}}$ is large (because naked adjudication would lead to excessive spending) and when litigation costs are not too high (for otherwise they would prefer to settle out of court). The rent-seeking model has the further empirical prediction, however, that a high-low agreement will cause the parties to reduce their subsequent litigation expenditures. One possible (and potentially observable) consequence, therefore, would be a decline (or a slower increase relative to those claims not governed by a high-low agreement) in litigation expenditures by both parties after a high-low agreement.

To evaluate this prediction, we examined whether monthly litigation expenditures for claims with high-low agreements in place were lower, all else equal, after the parties entered into the agreements. In particular, we regressed claimlevel monthly total litigation expenditures (and outside-counsel fees) on an indicator that a high-low agreement was concluded, claim-specific effects, claim

\footnotetext{
${ }^{65}$ The plaintiff's payoff at trial is $\left[\pi+\beta\left(e_{\mathrm{p}}^{.5}-e_{\mathrm{d}}^{.5}\right)\right] x_{\mathrm{H}}+\left[1-\pi-\beta\left(e_{\mathrm{p}}^{.5}-e_{\mathrm{d}}^{.5}\right)\right] x_{\mathrm{L}}-e_{\mathrm{p}}-c_{\mathrm{p}}$. Differentiating this expression gives the expression for $e_{\mathrm{p}}$ in the text. Similarly, one can derive $e_{\mathrm{d}}$.

${ }^{66}$ The joint benefit of going to trial is $\left(\pi_{\mathrm{p}}-\pi_{\mathrm{d}}\right)\left(s_{\mathrm{H}}-s_{\mathrm{L}}\right)-\left(\beta^{2} / 2\right)\left(s_{\mathrm{H}}-s_{\mathrm{L}}\right)^{2}-c_{\mathrm{p}}-c_{\mathrm{d}}$, where $c_{\mathrm{p}}$ and $c_{\mathrm{d}}$ are fixed litigation costs. Differentiating this expression with respect to $s_{\mathrm{H}}-s_{\mathrm{L}}$ establishes the result.
} 
characteristics that vary over time, and time fixed effects. ${ }^{67}$ To account for any remaining unobservables and to test whether monthly litigation expenditures may simply have grown at a slower rate after the high-low agreement, we also compared the spending patterns in high-low cases with those in cases in which a high-low agreement was discussed or negotiated but never concluded. ${ }^{68}$ Despite exploring various error structures and alternative specifications, we found no consistent differences in monthly litigation expenses between claims with a binding high-low agreement in place and all others. ${ }^{69}$

Of course, even a precisely estimated zero effect would not repudiate our excessive-rent-seeking theory. Litigants may be able to identify claims that are likely to involve high-low agreements and so reduce or delay spending in advance of entering into such an agreement. Litigation costs may also be fixed in the short run, especially for litigants, like our insurer, that employ legal staffs. ${ }^{70}$ Still, our findings hint that limiting rent seeking may only rarely account for highlow agreements, and there are strong theoretical arguments to support that interpretation. Most prominent, private parties may have other commitment devices at their disposal to limit their litigation expenditures. For example, litigants can concede certain issues and litigate only the remaining ones, ${ }^{71}$ and litigants can -and do-write contracts that explicitly constrain the presentation of evidence, including restrictions on the number of witnesses or the hours or scope of testimony. In short, parties may not need high-low agreements to limit excessive rent seeking when they can do so directly through explicit contractual limitations on activities that are costly.

\section{Conclusion}

This article presents the first systematic study of high-low agreements, an increasingly popular contractual device in civil litigation in the United States. We show formally that when at least one party is risk averse and both litigants are sufficiently optimistic about their prospects at trial, high-low agreements may

\footnotetext{
${ }^{67}$ We also explore outside-counsel fees as a dependent variable because they may be more likely than total litigation expenditures (which have fixed components) to reflect immediate changes in spending.

${ }^{68}$ We assume that claims involving high-low discussions are sufficiently similar to claims with high-low agreements in place to serve as an appropriate comparison group. To the extent that discussions do not fail randomly, however, our estimates represent a combination of the effects of the high-low agreement and the unobserved differences between these two groups.

${ }^{69}$ The rent-seeking story might imply that litigants would adopt high-low agreements early in the litigation process, before significant investments have been made. This is not true empirically. As shown in Table 3, high-low agreements are reached on average at 31.91 months into the dispute, which is approximately 80 percent of the time to trial.

${ }^{70}$ Monthly expenditure totals may also be less reliable than overall spending totals, as expenditures may be recorded months after commitments to pay for goods or services were made.

${ }^{71}$ See Noyes (2006) for a discussion of courts' acceptance of contracts that waive statutory rights and rules, such as waivers of notice and hearing and contracts that modify discovery requirements and limitations.
} 
arise endogenously because they can eliminate extreme outcomes while still allowing scope for mutually profitable disagreement. We evaluate this proposition empirically using insurance claims data and find that high-low discussions and agreements are relatively more common when outcomes are more uncertain and expected litigation costs are low. Our results are statistically and practically significant and robust to alternative specifications.

Our work moves beyond the existing literature on settlement in civil litigation, which primarily focuses on only the extreme ends of the dispute resolution spectrum-cases that are fully settled or dropped and cases that proceed to fullblown trial. In reality, dispute resolution occurs on a continuum. For example, to reduce costs, parties can opt to arbitrate (in essence, agree to ignore certain procedural requirements and waive the need for judges and juries in favor of third-party fact finders). Likewise, parties can agree to stipulate to certain facts or points of law while still allowing a judge or jury to decide many key issues. These practices make plain that settlement behavior in litigation includes far more than simply out-of-court settlement. ${ }^{72}$

High-low agreements (and incomplete settlement arrangements generally) also raise public policy issues that deserve attention but that are beyond the scope of this article. For instance, because these private agreements mitigate the risk of trial for litigants, they decrease the attractiveness of full settlement, and therefore they should increase the demand for trials (constrained by high-low agreements) that require courts and other publicly provided resources. Furthermore, because litigants are not required to disclose the existence of a high-low agreement, the availability of these arrangements may lead to a misallocation of scarce adjudicatory resources if judges or juries make decisions on the assumption that disputes involve greater stakes than they actually do. ${ }^{73}$

\section{Appendix A}

\section{Additional Data Description}

The insurer, which insisted on anonymity as a condition of allowing us to use its data, provided us with detailed information on all claims that were either closed or open at any point between January 1, 2004, and March 31, 2009. The raw claims data included approximately 570,000 total claims. Because we do not know how open claims were eventually resolved or will resolve, we do not use them in our analysis. By also removing claims that were missing extensive in-

\footnotetext{
${ }^{72}$ Of course, the cost-reducing benefits of arbitration are well recognized, but arbitration's relationship to the broader class of settlement contracts and the risk-reducing mechanisms that we highlight here, such as high-low agreements, remains underdeveloped.

${ }_{73}$ Additional distortions may arise for jurisdictional reasons. For example, imagine a lawsuit alleging $\$ 100,000$ in damages, above the $\$ 75,000$ federal jurisdiction amount-in-controversy requirement. If a secret high-low agreement limits possible damages to between $\$ 40,000$ and $\$ 60,000$, the effective amount in controversy is only $\$ 20,000$. One can even imagine an out-of-court full settlement (for example, a \$50,000 payment regardless) between parties who seek, on the public's dime, a jury's determination of who was right, after all.
} 
formation or were outliers in subject matter, geography, or timing, we constructed a clean data set of approximately 385,000 claims.

The clean data set consists of two types of claims: claims resolved administratively through a claim handler and disputed claims. For our purposes, we define a claim as being in dispute if either (1) positive litigation costs are recorded by the insurer's in-house legal counsel or an outside firm or (2) a suit date is recorded (which occurs when the insurer receives notice that the plaintiff has filed a complaint, at which point the insurer refers to the claim as being in suit). A little more than 12 percent, or about 48,350, of the claims were in dispute using our definition. Approximately 5 percent of the disputed claims, or about 2,600 claims, were actually litigated (resolved by trial or arbitration). Most nonadministrative claims involve both a suit date and positive litigation costs, but a small fraction involve only one or the other. In Table A3, we provide summary statistics for the data, and we include alternative broad and narrow measures of the disputed claims category by using the union and intersection of conditions 1 and 2 , respectively.

When a claimant notifies the insurer of a claim against one of its policies, the insurer first internally assesses the claim to determine to what extent, if any, the policyholder is responsible for the alleged harm. On the basis of this determination, the insurer attempts to resolve the claim through one of its claims agents. Most claims are resolved in this way, essentially administratively. If the claims agent is unable to resolve the claim through negotiation, and the claimant subsequently files suit, the insurer continues in its efforts to settle the claim but assigns either its own in-house legal staff or outside legal counsel to manage the claim. Consistent with most litigation, suits against the insurer typically end in settlement, with a small percentage proceeding to trial or arbitration.

For each claim it receives, the insurer records the date of the alleged harm, the date the insurer received notice of the claim, and the close date (that is, when the claim is resolved, regardless of its disposition). With these dates, it is possible to calculate the duration of each claim. In addition, the insurer gathers detailed information about the alleged harm and its likely litigation value. Of particular interest, the insurance company makes an initial assessment of the harm and the extent of its perceived liability but also subsequently records a second prelitigation evaluation of the likely value of the claim. It also records the state (and sometimes city) in which the accident or harm occurred and maintains demographic information about the area in which the insured and claimant (plaintiff) lives or lived. For all claims, the insurer also documents the amount it ultimately paid out, if anything, to the claimant, as well as any legal fees or other legal expenses it incurred along the way. Each record also contains the policy limit for the policyholder (which affects how the insurer handles the claim) and information about how long the insured had been covered by the policy and when it became effective.

For approximately 80 percent of the claims, the insurer noted whether the plaintiff was an individual or a business. The company also records extremely 
Table A1

Additional Summary Statistics: Litigated and High-Low Claims

\begin{tabular}{|c|c|c|c|}
\hline & $\begin{array}{c}\text { Trial or } \\
\text { Arbitration }\end{array}$ & $\begin{array}{l}\text { High-Low } \\
\text { Discussions }\end{array}$ & $\begin{array}{l}\text { High-Low } \\
\text { Agreements }\end{array}$ \\
\hline$N$ & 2,636 & 935 & 246 \\
\hline \multicolumn{4}{|l|}{ Claims by year closed: } \\
\hline 2004 & 312 & 138 & 27 \\
\hline 2005 & 450 & 150 & 28 \\
\hline 2006 & 558 & 180 & 53 \\
\hline 2007 & 574 & 206 & 68 \\
\hline 2008 & 615 & 230 & 61 \\
\hline 2009 & 127 & 31 & 9 \\
\hline \multicolumn{4}{|l|}{ Type of claim: } \\
\hline Auto liability & 983 & 590 & 165 \\
\hline General liability & 1,653 & 345 & 81 \\
\hline \multicolumn{4}{|l|}{ Region where claim arose $(\%)$ : } \\
\hline Northeast & 41.08 & 68.02 & 68.70 \\
\hline South & 26.25 & 13.90 & 15.85 \\
\hline Midwest & 8.88 & 6.84 & 6.10 \\
\hline West & 23.18 & 10.91 & 8.94 \\
\hline Pacific & .57 & .32 & .41 \\
\hline \multicolumn{4}{|l|}{ Claimant characteristics: } \\
\hline \multicolumn{4}{|l|}{ Claimant type (\%): } \\
\hline Firm or business & 10.1 & 1.5 & 2.4 \\
\hline Individual & 86.3 & 92.1 & 91.1 \\
\hline Unknown & 3.6 & 6.4 & 6.5 \\
\hline \multicolumn{4}{|l|}{ Part of body injured (\%): } \\
\hline Fatality & 2.2 & 1.6 & .4 \\
\hline Head & 5.8 & 8.5 & 7.7 \\
\hline Lower extremities & 13.0 & 14.2 & 15.5 \\
\hline Multiple injuries & 3.2 & 1.1 & .4 \\
\hline Neck & 13.0 & 9.4 & 8.9 \\
\hline Spinal & 4.4 & 10.6 & 11.4 \\
\hline Trunk & 24.3 & 38.3 & 38.2 \\
\hline Upper extremities & 8.2 & 12.7 & 12.6 \\
\hline Personal injury & 4.8 & 1.1 & 1.6 \\
\hline Unreported & 21.2 & 2.6 & 3.3 \\
\hline \multicolumn{4}{|l|}{ Average claim characteristics: } \\
\hline Duration of claim (months) & $\begin{array}{c}28.45 \\
(19.02)\end{array}$ & $\begin{array}{c}37.28 \\
(18.49)\end{array}$ & $\begin{array}{c}39.43 \\
(15.79)\end{array}$ \\
\hline Initial reserve $(\$)$ & $\begin{array}{c}7,012 \\
(13,474)\end{array}$ & $\begin{array}{c}7,055 \\
(12,425)\end{array}$ & $\begin{array}{c}5,683 \\
(8,876)\end{array}$ \\
\hline \multirow[t]{2}{*}{ Loss paid (\$) } & 32,392 & 93,426 & 87,876 \\
\hline & $(126,757)$ & $(174,682)$ & $(140,041)$ \\
\hline Insurer litigation costs $(\$)$ & $\begin{array}{c}13,880 \\
(34,280)\end{array}$ & $\begin{array}{c}14,215 \\
(31,792)\end{array}$ & $\begin{array}{c}12,662 \\
(20,736)\end{array}$ \\
\hline \multirow[t]{2}{*}{ Policy limit per person $(\$)$} & 974,916 & 632,594 & 542,277 \\
\hline & $(879,177)$ & $(740,183)$ & $(614,334)$ \\
\hline \multirow[t]{2}{*}{ Policy limit per event (\$) } & $1,389,592$ & 878,318 & 795,281 \\
\hline & $(2,394,692)$ & $(801,791)$ & $(791,954)$ \\
\hline
\end{tabular}

Note. Values are computed from machine data or litigation notes provided by the insurer. Financial values are reported in 2008 dollars. Claims with high-low discussions include claims in which the parties at least raised in settlement negotiations the possibility of a high-low agreement. Claims with a high-low agreement include claims with high-low discussions in which the parties reached an actual agreement. Because some high-low agreements were subsequently resolved through settlement, claims resolved through trial or arbitration include some but not all of the high-low discussions and agreements. Standard deviations are in parentheses. 


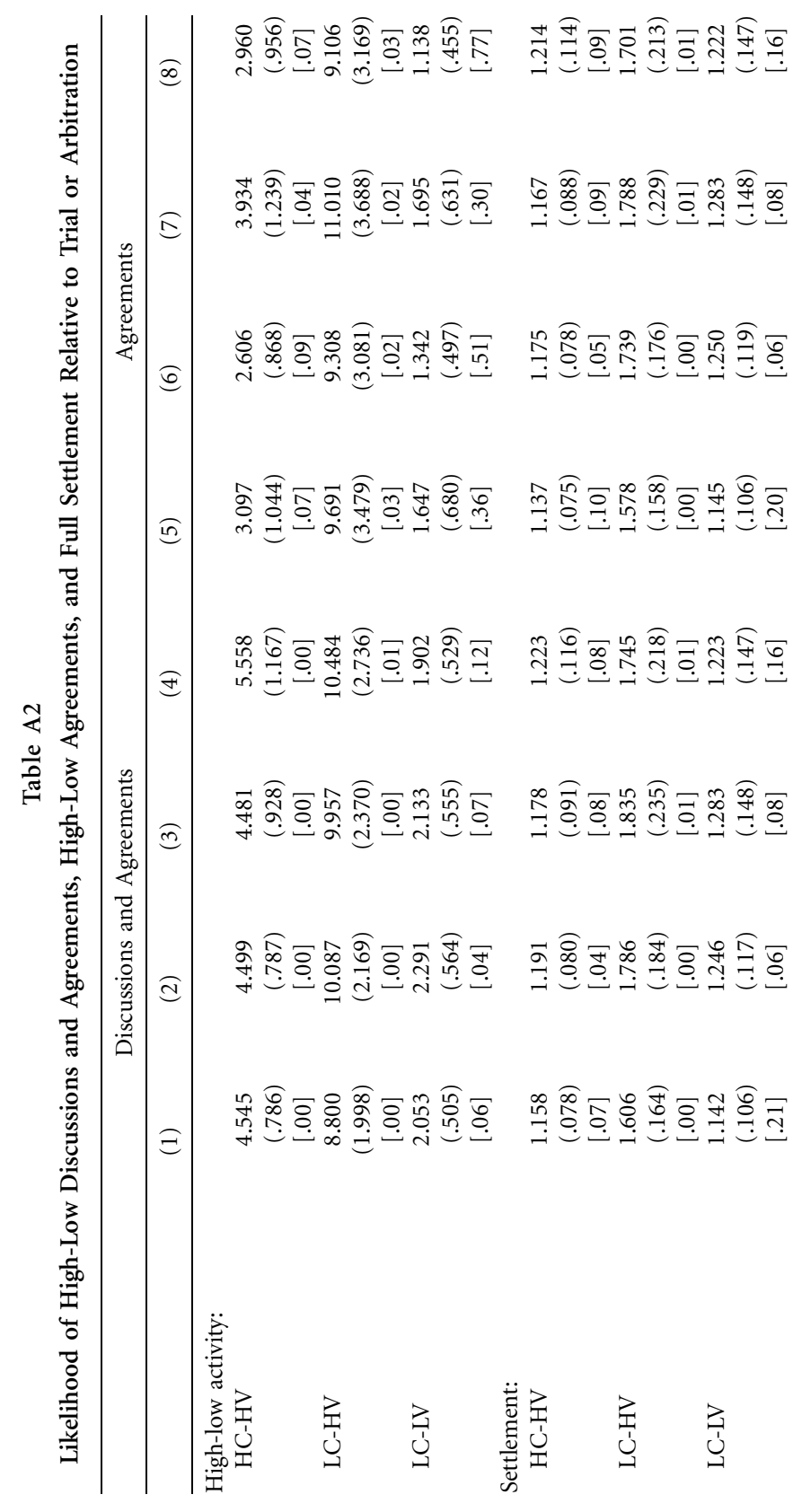




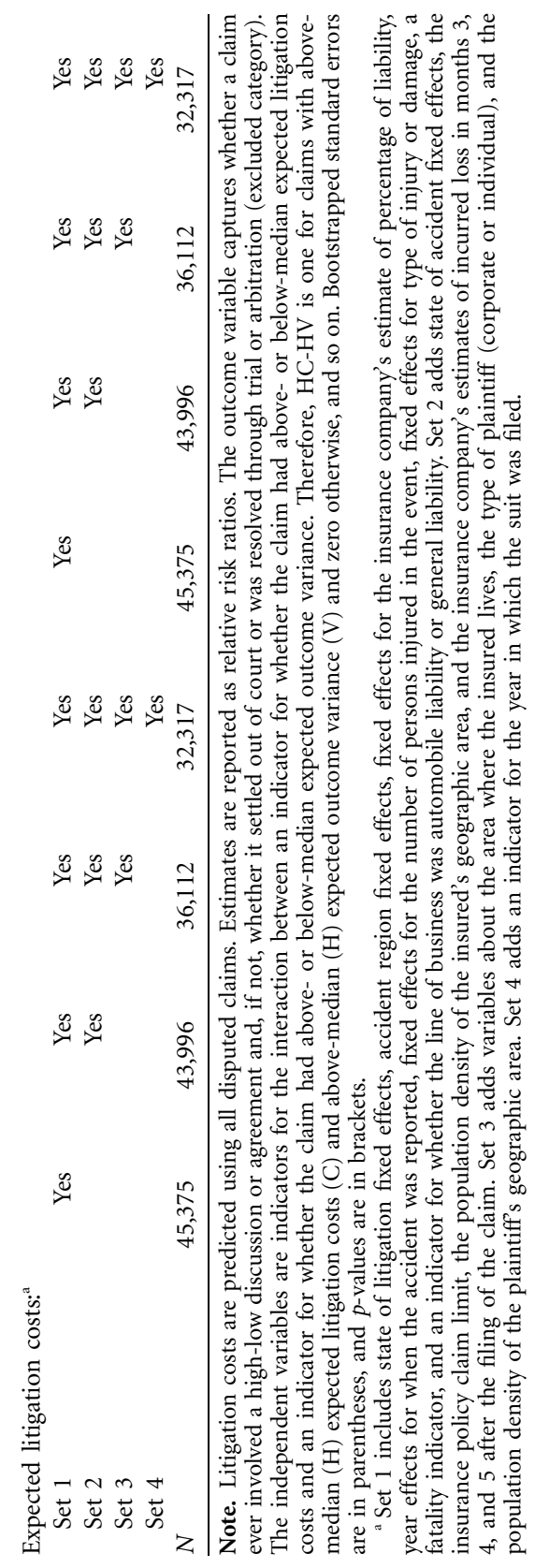




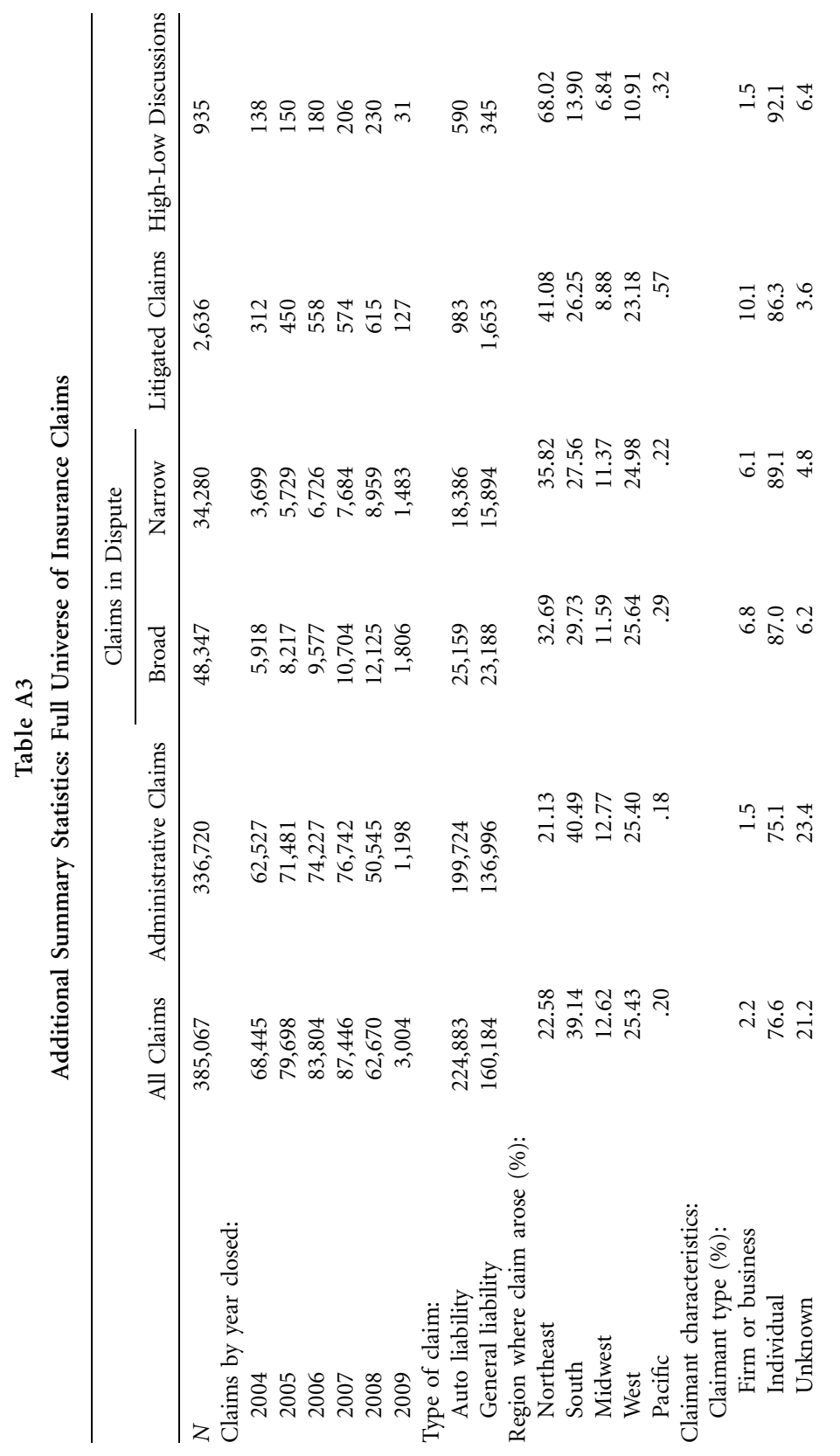




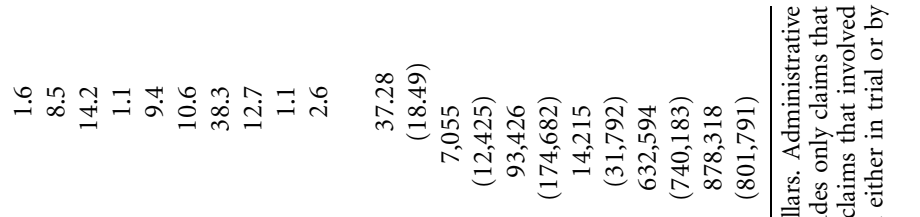

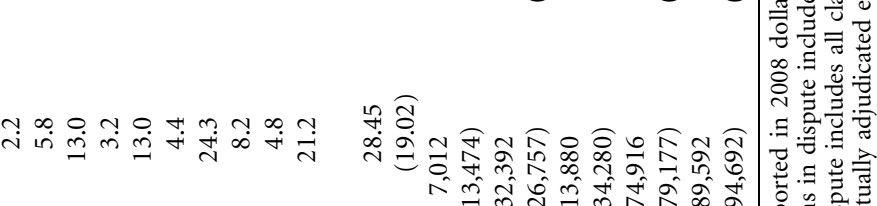

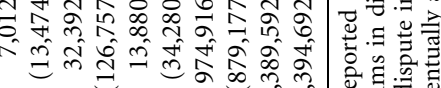

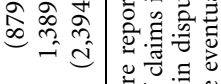

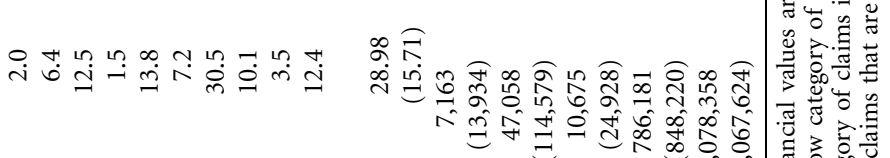

$$
\begin{aligned}
& \text { 事 }
\end{aligned}
$$

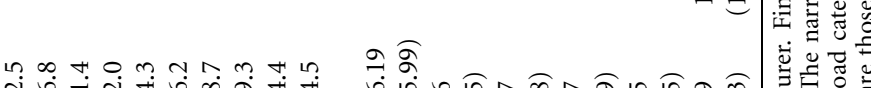

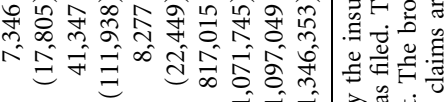

$$
\begin{aligned}
& =
\end{aligned}
$$

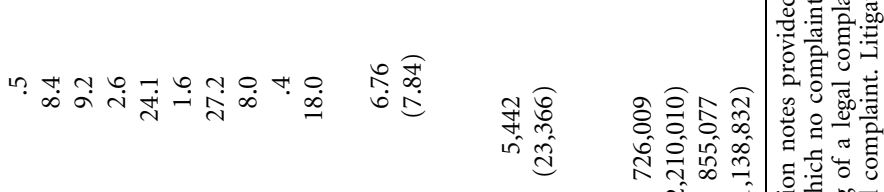

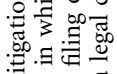

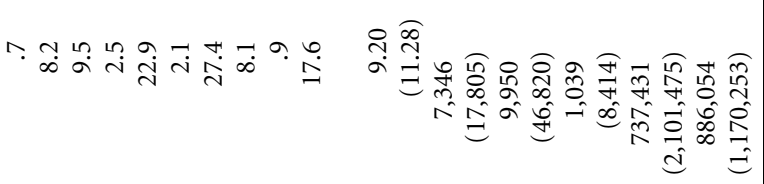

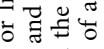

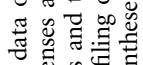

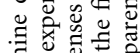

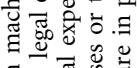

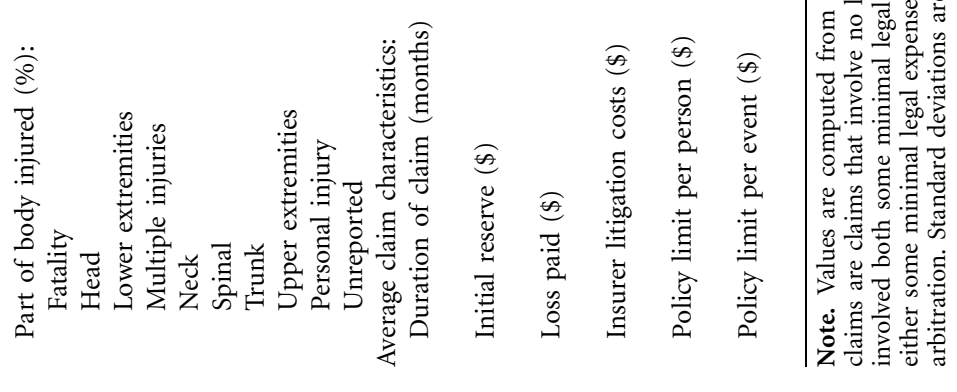


detailed information about the type of harm allegedly suffered by the plaintiff. Possible harms include property (or economic) damage, personal injury or death, or, in many instances, both. Property or economic damage and personal injury raise different concerns for the insurer. With property or economic damage, the magnitude of harm is typically quantifiable using market measures, leaving liability as the central issue. By contrast, claims involving personal injury require the insurer to determine both the magnitude of the harm as well as the extent of liability, so the insurer catalogs the part of the body allegedly harmed (for example, head, neck, spine) as well as the nature of the injury (for example, contusion, sprain, fracture). If there are multiple injuries, the insurer notes them, as well as whether other people were injured during the loss event and other indicators of injury (the use of an ambulance, for example).

As the summary statistics in Table A3 suggest, in-dispute claims are different from administratively handled claims. The fatality rate is more than four times higher in disputed claims than in administrative claims. In addition, a disputed claim takes on average four times longer to resolve and involves payouts eight times greater than an administrative claim. The insurer tracks how the claim resolved, whether by settlement, arbitration, or trial. Table 1 reports the same statistics as Table A3, broken down by whether the claim involved a high-low discussion (irrespective of whether the parties reached a high-low agreement or how the claim was ultimately resolved), was resolved through settlement without a high-low discussion, or was resolved by trial or arbitration without a highlow discussion. Consistent with existing literature on settlement rates (Galanter 1994), the vast majority of claims (95 percent) were resolved without formal adjudication.

The insurer does not store any of its settlement agreements (including even whether there was a written or oral high-low agreement in place) in its standard, uniformly coded and collected electronic records. However, the insurer does keep extensive electronic narrative records on how the claim is handled while it is in dispute. Claim handlers, lawyers, and anyone else involved with a claim enter their notes as claims evolve, although the notes are not entirely complete and can be difficult to decipher.

To extract information about high-low agreements from these notes (which run at least many dozens of pages per in-dispute claim when aggregated), we worked with the insurer to design an algorithm that extracted chunks of text surrounding references to a high-low agreement. The algorithm was designed to identify the many ways in which different people might have referred to highlow agreements in the notes: for example, "hi-lo," "high/low," and "hi/low."

A single claim often gave rise to several notes, depending on the frequency of high-low references. All notes included the following:

1. Event ID: the underlying event giving rise to one or more claims;

2. Claim ID: the specific claim corresponding to a given event;

3. Note ID: an individual identifier for the specific note; 
4. Note type: the category of note, for example, negotiation, legal, medical, and so on;

5. Note date: the date corresponding to the note; and

6. Note count: the total number of notes attached to the claim.

The algorithm also recorded how many times the variation of the term appeared in the claim notes. For privacy reasons, notes were redacted to exclude names, addresses, social security numbers, and other sensitive information.

We read through a large sample of complete case notes and algorithm-extracted chunks of text to better understand the scope of the notes and to design a coding regimen. Research assistants completed the coding and double-checking of the data. For each of these claims with relevant high-low agreement information, we read the available narrative information and recorded the context in which the high-low agreement arose, whether the parties reached an actual agreement, as well as other potentially useful information, such as the number of back-andforth proposals, relevant dates, and the proximity of the discussion to trial or arbitration, if apparent.

When the redactions inhibited our ability to understand the notes, we requested additional information from the insurer. Officials at the insurer either helped us to determine the substance of the notes or forwarded hand-redacted notes. These notes were then recombined with the existing notes for those claims. The same procedure was used for both auto and general liability claims. The high-low data were structured such that each row in a spreadsheet contained a new note and all of the information that we had about that note. The data were sorted by event ID to determine whether there were multiple claims for an event, then sorted by claim ID to group each claim together, then sorted by date so that the notes were in chronological order within each claim. We ultimately coded a total of almost 300,000 text entries (many for each claim).

From the claim notes identified and redacted by the text-mining algorithm, we collected the following information on high-low discussions and agreements:

$H-L$ Discussion Level. Measures the extent of high-low discussion. A 0 indicates that a high-low agreement was mentioned by the insurer but there was no discussion between the parties. A 1 indicates that a high-low agreement was mentioned by one party but the other party was not interested. A 2 indicates that an arrangement was discussed and seriously considered by both sides but that no high-low agreement was ever reached. Any interest on the part of opposing counsel (such as "let me check with my client") received a 2 coding. A 3 indicates that a high-low agreement was made. A 4 indicates that the interest level is unknown or unclear.

Party Type. Identifies the party initiating the high-low discussion. A 1 indicates that the insurer raised the possibility of a high-low agreement. A 2 means that the plaintiff raised the possibility. A 3 indicates that a codefendant (such as another insurance company also involved in the litigation) proposed the idea. A 4 means that it is unclear from the notes which party raised the possibility. A 5 indicates that a judge raised the notion. 
Date H-L Raised. Captures the date of the first registered mention of a highlow agreement.

$H-L$ Context. Records the stage of the litigation at which the discussion of the high-low agreement occurred. A 0 represents a very early planning/negotiation stage, 1 is for arbitration, 2 is for mediation, and 3 is for trial.

Date H-L Reached. If applicable, catalogs the date on which the parties agreed to a high-low arrangement.

High. If applicable, contains the high of the agreement.

Low. If applicable, contains the low of the agreement.

Claim Resolution. Categorizes how the claim was eventually resolved. A 1 is for arbitration, a 2 is for mediation, a 3 is for trial, a 4 is for settlement, a 5 is for a dismissal or dropped case, and a 6 is for when the notes did not provide sufficient information to determine the resolution.

In the rare event that claims involved multiple parties and multiple distinct high-low agreements, we recorded the information in multiple separate rows as if there were separate agreements on potentially distinct claims. We then determined the appropriate treatment on the basis of the facts and procedural posture of the case.

We also collected information on whether a claim involved multiple high-low proposals, and, if so, we recorded the terms of each offer or demand, up to three proposals. (In a few instances, the notes did not report the actual terms of any high-low proposal.) These proposals usually, but not necessarily, resulted in the parties reaching a high-low agreement. Finally, we kept track of any information indicating the motivation or thinking of the lawyers or other insurer personnel in engaging in a high-low negotiation or agreement and also recorded any other information possibly relevant to analyzing the case.

As an internal check, many claims (several hundred) were coded redundantly to ensure accuracy. Subsequent spot-checking also revealed that coding was highly consistent. Research assistants also recorded the certainty of their coding. A claim coded as a 1 was evaluated by another research assistant or by one of us, a 2 indicated that the claim required additional attention, and a 3 meant that the research assistant had high confidence in the coding.

\section{Appendix B}

\section{Proofs of Lemma 1 and Proposition 1}

\section{B1. Proof of Lemma 1}

Using equation (1), the award-modification contract would satisfy

$$
\frac{\pi_{\mathrm{p}} a_{\mathrm{p}} e^{-a_{\mathrm{p}}\left(s_{\mathrm{H}}-c_{\mathrm{p}}-k_{\mathrm{p}}\right)}}{\left(1-\pi_{\mathrm{p}}\right) a_{\mathrm{p}} e^{-a_{\mathrm{p}}\left(s_{\mathrm{L}}-c_{\mathrm{p}}-k_{\mathrm{p}}\right)}}=\frac{\pi_{\mathrm{d}} a_{\mathrm{d}} e^{-a_{\mathrm{d}}\left(-s_{\mathrm{H}}-c_{\mathrm{d}}-k_{\mathrm{d}}\right)}}{\left(1-\pi_{\mathrm{d}}\right) a_{\mathrm{d}} e^{-a_{\mathrm{d}}\left(-s_{\mathrm{L}}-c_{\mathrm{d}}-k_{\mathrm{d}}\right)}} .
$$

The litigation and negotiation costs drop out, which gives 


$$
\frac{\pi_{\mathrm{p}} e^{-a_{\mathrm{p}} s_{\mathrm{H}}}}{\left(1-\pi_{\mathrm{p}}\right) e^{-a_{\mathrm{p}} s_{\mathrm{L}}}}=\frac{\pi_{\mathrm{d}} e^{a_{\mathrm{d}} s_{\mathrm{H}}}}{\left(1-\pi_{\mathrm{d}}\right) e^{a_{\mathrm{d}} s_{\mathrm{L}}}} .
$$

Rearranging this expression yields

$$
\left[\frac{\left(1 / \pi_{\mathrm{d}}\right)-1}{\left(1 / \pi_{\mathrm{p}}\right)-1}\right]=e^{\left(a_{\mathrm{p}}+a_{\mathrm{d}}\right)\left(s_{\mathrm{H}}-s_{\mathrm{L}}\right)} .
$$

Taking the natural logarithm of both sides and rearranging terms gives the result. Q.E.D.

\section{B2. Proof of Proposition 1}

We first characterize the situations in which the parties would jointly prefer settlement to a naked trial. Suppose there is an ordinary settlement contract, $s$, that is better for both litigants. For the plaintiff, it must be the case that

$$
-\exp \left[-a_{\mathrm{p}} s\right]>-\pi_{\mathrm{p}} \exp \left[-a_{\mathrm{p}}\left(x_{\mathrm{H}}-c_{\mathrm{p}}\right)\right]-\left(1-\pi_{\mathrm{p}}\right) \exp \left[-a_{\mathrm{p}}\left(x_{\mathrm{L}}-c_{\mathrm{p}}\right)\right] .
$$

Rearranging terms, this establishes a lower bound, $\underline{s}$, for the settlement amount:

$$
\begin{aligned}
s>\underline{s} & =-c_{\mathrm{p}}-\left(1 / a_{\mathrm{p}}\right) \ln \left[\pi_{\mathrm{p}} e^{-a_{\mathrm{p}} x_{\mathrm{H}}}+\left(1-\pi_{\mathrm{p}}\right) e^{-a_{\mathrm{p}} x_{\mathrm{L}}}\right] \\
& =-c_{\mathrm{p}}+x_{\mathrm{L}}-\left(1 / a_{\mathrm{p}}\right) \ln \left[\pi_{\mathrm{p}} e^{-a_{\mathrm{p}}\left(x_{\mathrm{H}}-x_{\mathrm{L}}\right)}+1-\pi_{\mathrm{p}}\right] .
\end{aligned}
$$

Similarly for the defendant, settling must be better than going to trial, so

$$
-\exp \left[a_{\mathrm{d}} s\right]>-\pi_{\mathrm{d}} \exp \left[a_{\mathrm{d}}\left(x_{\mathrm{H}}+c_{\mathrm{d}}\right)\right]-\left(1-\pi_{\mathrm{d}}\right) \exp \left[a_{\mathrm{d}}\left(x_{\mathrm{L}}+c_{\mathrm{d}}\right)\right] .
$$

Rearranging terms, we establish an upper bound, $\bar{s}$, for the settlement amount:

$$
\begin{aligned}
s<\bar{s} & =c_{\mathrm{d}}+\left(1 / a_{\mathrm{d}}\right) \ln \left[\pi_{\mathrm{d}} e^{a_{\mathrm{d}} x_{\mathrm{H}}}+\left(1-\pi_{\mathrm{p}}\right) e^{a_{\mathrm{d}} x_{\mathrm{L}}}\right] \\
& =c_{\mathrm{d}}+x_{\mathrm{L}}+\left(1 / a_{\mathrm{d}}\right) \ln \left[\pi_{\mathrm{d}} e^{a_{\mathrm{d}}\left(x_{\mathrm{H}}-x_{\mathrm{L}}\right)}+1-\pi_{\mathrm{d}}\right] .
\end{aligned}
$$

So a mutually acceptable settlement amount exists if and only if $\underline{s}<\bar{s}$, or when

$$
c_{\mathrm{p}}+c_{\mathrm{d}}>-\left(1 / a_{\mathrm{p}}\right) \ln \left[1-\pi_{\mathrm{p}}+\pi_{\mathrm{p}} e^{-a_{\mathrm{p}}\left(x_{\mathrm{H}}-x_{\mathrm{L}}\right)}\right]-\left(1 / a_{\mathrm{d}}\right) \ln \left[1-\pi_{\mathrm{d}}+\pi_{\mathrm{d}} e^{a_{\mathrm{d}}\left(x_{\mathrm{H}}-x_{\mathrm{L}}\right)}\right] .
$$

We rename the right-hand side $\phi\left(x_{\mathrm{H}}-x_{\mathrm{L}} ; \pi_{\mathrm{p}}, \pi_{\mathrm{d}}, a_{\mathrm{p}}, a_{\mathrm{d}}\right)$, and we suppress notation and rewrite it as $\phi\left(x_{\mathrm{H}}-x_{\mathrm{L}}\right)$. Note that $\phi(0)=0$. Differentiating $\phi\left(x_{\mathrm{H}}-x_{\mathrm{L}}\right)$ tells us that it is increasing if and only if

$$
\frac{\pi_{\mathrm{p}} e^{-a_{\mathrm{p}}\left(x_{\mathrm{H}}-x_{\mathrm{L}}\right)}}{1-\pi_{\mathrm{p}}+\pi_{\mathrm{p}} e^{-a_{\mathrm{p}}\left(x_{\mathrm{H}}-x_{\mathrm{L}}\right)}}-\frac{\pi_{\mathrm{d}} e^{-a_{\mathrm{d}}\left(x_{\mathrm{H}}-x_{\mathrm{L}}\right)}}{1-\pi_{\mathrm{d}}+\pi_{\mathrm{d}} e^{-a_{\mathrm{d}}\left(x_{\mathrm{H}}-x_{\mathrm{L}}\right)}}>0,
$$

which is true if and only if

$$
\frac{\left(1-\pi_{\mathrm{d}}\right) / \pi_{\mathrm{d}}}{\left(1-\pi_{\mathrm{p}}\right) / \pi_{\mathrm{p}}}>e^{\left(a_{\mathrm{p}}+a_{\mathrm{d}}\right)\left(x_{\mathrm{H}}-x_{\mathrm{L}}\right)}
$$

or, equivalently, $x_{\mathrm{H}}-x_{\mathrm{L}}<\Delta^{*}$, where $\Delta^{*}$ is defined in the text.

When $\pi_{\mathrm{p}}<\pi_{\mathrm{d}}$, then $\Delta^{*}<0$. Since $\phi\left(x_{\mathrm{H}}-x_{\mathrm{L}}\right)$ is a decreasing function for all $x_{\mathrm{H}}-x_{\mathrm{L}}>\Delta^{*}$ and $\phi(0)=0$, we conclude that $\phi\left(x_{\mathrm{H}}-x_{\mathrm{L}}\right)<0$ for all $x_{\mathrm{H}}-$ 
$x_{\mathrm{L}}>0$. So the parties would prefer settlement to a naked trial. If contracts were unrestricted, they might want to sign a contract with $s_{\mathrm{L}}>s_{\mathrm{H}}$. Under assumption 1 , the constraint that $s_{\mathrm{L}} \leq s_{\mathrm{H}}$ is binding, so the parties can do no better than settling out of court.

When $\pi_{\mathrm{p}}<\pi_{\mathrm{d}}$, then $\Delta^{*}>0$. When $x_{\mathrm{H}}-x_{\mathrm{L}} \in\left(0, \Delta^{*}\right)$, then $\phi\left(x_{\mathrm{H}}-x_{\mathrm{L}}\right)>0$. The Pareto-optimal contract modification $s_{\mathrm{H}}-s_{\mathrm{L}}=\Delta^{\star}>x_{\mathrm{H}}-x_{\mathrm{L}}$ would amplify the risk at trial, violating assumption 1 . So for $x_{\mathrm{H}}-x_{\mathrm{L}} \in\left(0, \Delta^{*}\right)$, the parties would never opt for a high-low agreement. In this region, the parties will either settle out of court or pursue a naked trial. When $x_{\mathrm{H}}-x_{\mathrm{L}}>\Delta^{*}$, then the contract $s_{\mathrm{H}}-s_{\mathrm{L}}=\Delta^{\star}<x_{\mathrm{H}}-x_{\mathrm{L}}$ does not violate assumption 1 . The parties will prefer a high-low contract with $s_{\mathrm{H}}-s_{\mathrm{L}}=\Delta^{*}$ to a naked trial when the joint net value of the high-low contract is larger than the joint value of a naked trial, or

$$
\phi\left(\Delta^{*}\right)-\left(c_{\mathrm{p}}+c_{\mathrm{d}}\right)-\left(k_{\mathrm{p}}+k_{\mathrm{d}}\right)>\phi\left(x_{\mathrm{H}}-x_{\mathrm{L}}\right)-\left(c_{\mathrm{p}}+c_{\mathrm{d}}\right)
$$

or, equivalently,

$$
\phi\left(x_{\mathrm{H}}-x_{\mathrm{L}}\right)<\phi(\tilde{\Delta})=\phi\left(\Delta^{\star}\right)-\left(\mathrm{k}_{\mathrm{p}}+k_{\mathrm{d}}\right) .
$$

The value $\tilde{\Delta}>\Delta^{\star}$ exists because $\phi\left(x_{\mathrm{H}}-x_{\mathrm{L}}\right)$ decreases without bound when $x_{\mathrm{H}}-x_{\mathrm{L}}$ goes to infinity. Finally, $\phi(\tilde{\Delta})>0$ when $k_{\mathrm{p}}+k_{\mathrm{d}}<\phi\left(\Delta^{*}\right)$. When $x_{\mathrm{H}}-$ $x_{\mathrm{L}}>\tilde{\Delta}$, the parties will pursue trial with a high-low agreement when $c_{\mathrm{p}}+c_{\mathrm{d}}<$ $\phi\left(\Delta^{\star}\right)-\left(k_{\mathrm{p}}+k_{\mathrm{d}}\right)$ and will settle out of court when $c_{\mathrm{p}}+c_{\mathrm{d}}>\phi\left(\Delta^{\star}\right)-\left(k_{\mathrm{p}}+\right.$ $\left.k_{\mathrm{d}}\right)$. Q.E.D.

\section{References}

Administrative Office of the U.S. Courts. 2002. Judicial Business of the United States Courts, Annual Report 2001. Washington, D.C.: Administrative Office of the U.S. Courts. http: //www.uscourts.gov/uscourts/FederalCourts/AnnualReport/2001.pdf.

Bar-Gill, Oren. 2006. Evolution and Persistence of Optimism in Litigation. Journal of Law, Economics, and Organization 22:490-507.

Bebchuk, Lucian A. 1984. Litigation and Settlement under Imperfect Information. RAND Journal of Economics 15:404-15.

Black, Bernard, David A. Hyman, Charles Silver, and William M. Sage. 2008. Defense Costs and Insurer Reserves in Medical Malpractice and Other Personal Injury Cases: Evidence from Texas, 1988-2004. American Law and Economics Review 10:185-245.

Briys, Eric, Michel Crouhy, and Rainer Schobel. 1991. The Pricing of Default Free Interest Rate Cap, Floor, and Collar Agreements. Journal of Finance 46:1879-92.

Clermont, Kevin M., and Stewart J. Schwab. 2008. Employment Discrimination Plaintiffs in Federal Court: From Bad to Worse? Harvard Law and Policy Review 3:103-32.

Cooter, Robert D., and Daniel L. Rubinfeld. 1989. Economic Analysis of Legal Disputes and Their Resolution. Journal of Economic Literature 27:1067-97.

Coulson, Robert. 1968. Negotiating Control Contracts: Trial Counsel Reduce Their Need for Appeals. Judicature 52:190-93.

Danzon, Patricia M., and Lee A. Lillard. 1983. Settlement out of Court: The Disposition of Medical Malpractice Claims. Journal of Legal Studies 12:345-77.

Daughety, Andrew F. 2000. Settlement. Pp. 95-158 in volume 5 of Encyclopedia of Law 
and Economics, edited by Boudewijn Bouckaert and Gerrit De Geest. Cheltenham: Edward Elgar.

Dixit, Avinash. 1987. Strategic Behavior in Contests. American Economic Review 77:89198.

Donohue, John. 1991. Opting for the British Rule, or If Posner and Shavell Can't Remember the Coase Theorem, Who Will? Harvard Law Review 104:1093-1119.

Eisenberg, Theodore, and Henry Farber. 1997. The Litigious Plaintiff Hypothesis. RAND Journal of Economics 28:S92-S112.

Eisenberg, Theodore, and Charlotte Lanvers. 2008. What Is the Settlement Rate and Why Should We Care? Journal of Empirical Legal Studies 6:111-46.

Emerick, Charles. 2007. High-Low Agreement Negates Jackson County Jury Verdict for Crash Injuries. Daily Record (Kansas City, Mo.), August 28.

Faley, Kevin G., and Andrea M. Alonso. 1998. High-Low Agreements: Misunderstood Litigation Technique. New York Law Journal, March 27.

Farber, Henry, and Michelle White. 1991. Medical Malpractice: An Empirical Investigation of the Litigation Process. RAND Journal of Economics 22:199-217.

Farmer, Amy, and Paul Pecorino. 1994. Pretrial Negotiations with Asymmetric Information on Risk Preferences. International Review of Law and Economics 14:273-81.

Fenn, Paul, and Niel Rickman. 1999. Delay and Settlement in Litigation. Economic Journal 109:476-91.

Finz, Leonard. 1976. A Trial Where Both Sides Win. Judicature 59:41-44.

Fournier, Gary M., and Thomas W. Zuehlke. 1996. The Timing of Out of Court Settlement. RAND Journal of Economics 27:310-21.

Fuller, Kathleen P. 2003. Why Some Firms Use Collar Offers in Mergers. Financial Review 38:127-50.

Galanter, Marc, and Mia Cahill. 1994. Most Cases Settle: Judicial Promotion and Regulation of Settlements. Stanford Law Review 46:1339-91.

Garner, Bryan A., ed. 2004. Black's Law Dictionary. St. Paul, Minn.: West Group.

Gaver, Jennifer J., and Jeffrey S. Paterson. 2007. The Influence of Large Clients on OfficeLevel Auditor Oversight: Evidence from the Property-Casualty Insurance Industry. Journal of Accounting and Economics 43:299-320.

Gould, John. 1973. The Economics of Legal Conflicts. Journal of Legal Studies 2:279-300.

Grace, Elizabeth. 1990. Property-Liability Insurer Reserve Errors: A Theoretical and Empirical Analysis. Journal of Risk and Insurance 57:28-46.

Gross, Samuel R., and Kent D. Syverud. 1996. Don't Try: Civil Jury Verdicts in a System Geared to Settlement. UCLA Law Review 44:1-64.

Gruber, Jonathan, and Aaron Yelowitz. 1999. Public Health Insurance and Private Saving. Journal of Political Economy 107:1249-74.

Hadfield, Gillian K. 2004. Where Have All the Trials Gone? Settlements, Nontrial Adjudications, and Statistical Artifacts in the Changing Disposition of Federal Civil Cases. Journal of Empirical Legal Studies 1:705-34.

Hannaford-Agor, Paula L. 2012. Short, Summary and Expedited: The Evolution of Civil Jury Trials. National Center for State Courts, Williamsburg, Va. http://www.ncsc.org / /media/Files/PDF/Information\%20and\%20Resources/Civil\%20cover\%20sheets /ShortSummaryExpedited-online\%20rev.ashx.

Hansen, Robert G. 1987. A Theory of the Choice of Exchange Medium in Mergers and Acquisitions. Journal of Business 60:75-95.

Hay, Bruce, and Kathryn E. Spier. 1998. Settlement of Litigation. Pp. 442-51 in volume 
3 of The New Palgrave Dictionary of Economics and the Law, edited by Peter Newman. London: Macmillan Reference Ltd.

Heyes, Anthony, Neil Rickman, and Dionisia Tzavara. 2004. Legal Expenses, Risk Aversion, and Litigation. International Review of Law and Economics 24:107-19.

Hoenig, Michael. 2006. Secret "High-Low" Agreements. New York Law Journal, October 11, p. 3.

Houston, Joel F., and Michael D. Ryngaert. 1997. Equity Issuance and Adverse Selection: A Direct Test Using Conditional Stock Offers. Journal of Finance 52:197-219.

Hughes, James, and Edward Snyder. 1995. Litigation and Settlement under the English and American Rules: Theory and Evidence. Journal of Law and Economics 38:225-50.

Imbens, Guido, and Jeffrey Wooldridge. 2007. Control Function and Related Methods. What's New in Econometrics, Lecture Notes 6. National Bureau of Economic Research, Cambridge, Mass. July 31. http://www.nber.org/WNE/lect_6_controlfuncs.pdf.

Jolly, Julius. 1928. Hindu Law and Custom. Greater India Society Publication No. 2. Translated by Batakrishma Ghosh. Calcutta: Greater India Society. Originally published in German, 1883.

Kessler, Daniel, Thomas Meites, and Geoffrey Miller. 1996. Explaining Deviations from the Fifty-Percent Rule: A Multimodal Approach to the Selection of Cases for Litigation. Journal of Legal Studies 25:233-59.

Kessler, Daniel, and Daniel Rubinfeld. 2004. Empirical Study of the Civil Justice System. Handbook of Law and Economics 1:343-402.

King, Gary, and Langche Zeng. 2001. Logistic Regression in Rare Events Data. Political Analysis 9:137-63.

Klement, Alon, and Zvika Neeman. 2005. Against Compromise: A Mechanism Design Approach. Journal of Law, Economics, and Organization 21:285-314.

Landes, William M. 1971. An Economic Analysis of the Courts. Journal of Law and Economics 14:61-107.

- 1993. Sequential versus Unitary Trials: An Economic Analysis. Journal of Legal Studies 22:99-134.

Loewenstein, George, Samuel Issacharoff, Colin Camerer, and Linda Babcock. 1993. SelfServing Assessments of Fairness and Pretrial Bargaining. Journal of Legal Studies 22: 135-58.

McDonough, Molly. 2005. High Lows' Ups and Downs. ABA Journal, August, pp. 12-13.

McGuire, Charles R. 1996. Should Banks Sell Insurance? The Relationship of Section 92 of the Banking Act, the McCarran-Ferguson Act and State Laws Restricting Bank Activity. Journal of Legislation 22:19-43.

Miller, Geoffrey P. 1987. Some Agency Problems in Settlement. Journal of Legal Studies 16:189-215.

Murphy, Kevin M., and Robert H. Topel. 1985. Estimation and Inference in Two-Step Econometric Models. Journal of Business and Economic Statistics 3:370-79.

Myers, Stewart C., and Nicholas Majluf. 1984. Corporate Financing and Investment Decisions When Firms Have Information Investors Do Not Have. Journal of Financial Economics 87:355-74.

Myerson, Roger. 1979. Incentive Compatibility and the Bargaining Problem. Econometrica 47:61-73.

Myerson, Roger, and Mark Satterthwaite. 1983. Efficient Mechanisms for Bilateral Trading. Journal of Economic Theory 29:265-81. 
Nalebuff, Barry. 1987. Credible Pretrial Negotiation. RAND Journal of Economics 18:198210.

Noyes, Henry S. 2006. If You (Re)Build It, They Will Come: Contracts to Remake the Rules of Litigation in Arbitration's Image. Harvard Journal of Law and Public Policy 30:579-647.

Officer, Micah S. 2004. Collars and Renegotiation in Mergers and Acquisitions. Journal of Finance 59:2719-43.

Ostrom, Brian J., Neal B. Kauder, and Robert C. LaFountain. 2001. Examining the Work of the State Courts, 1999-2000. National Center for State Courts, Williamsburg, Va.

Petroni, Kathy R. 1992. Optimally Reporting in the Property-Casualty Insurance Industry. Journal of Accounting and Economics 15:485-508.

Petroni, Kathy R., Stephen G. Ryan, and James M. Wahlen. 2000. Discretionary and Nondiscretionary Revisions of Loss Reserves by Property-Casualty Insurers: Differential Implications for Future Profitability, Risk, and Market Value. Review of Accounting Studies 5:95-125.

P'ng, Ivan P. L. 1983. Strategic Behavior in Suit, Settlement, and Trial. RAND Journal of Economics 14:539-50.

Posner, Richard A. 1973. An Economic Approach to Legal Procedure and Judicial Administration. Journal of Legal Studies 2:399-458.

Priest, George, and Benjamin Klein. 1984. The Selection of Disputes for Litigation. Journal of Legal Studies 13:1-55.

Reinganum, Jennifer, and Louise Wilde. 1986. Settlement, Litigation, and the Allocation of Litigation Costs. RAND Journal of Economics 17:557-68.

Riner, Duane. 1989. High-Low Pretrial Pact Praised, Ensures Some Funds for Plaintiffs. Atlanta Journal and Constitution, April 9.

Salzmann, Ruth E. 1984. Estimated Liabilities for Losses and Loss Adjustment Expenses. Englewood Cliffs, N.J.: Prentice Hall.

Shavell, Steven. 1982. Suit, Settlement and Trial: A Theoretical Analysis under Alternative Methods for the Allocation of Legal Costs. Journal of Legal Studies 11:55-82.

Shepherd, George B. 1999. An Empirical Study of the Economics of Pretrial Discovery. International Review of Law and Economics 19:245-63.

Sieg, Holger. 2000. Estimating a Bargaining Model with Asymmetric Information: Evidence from Medical Malpractice Disputes. Journal of Political Economy 108:1006-21.

Siegel, Ron. 2009. All-Pay Contests. Econometrica 77:71-92.

Siegelman, Peter, and Joel Waldfogel. 1999. Towards a Taxonomy of Disputes: New Evidence through the Prism of the Priest-Klein Hypothesis. Journal of Legal Studies 28: 101-29.

Snyder, Edward, and James Hughes. 1990. The English Rule for Allocating Legal Costs: Evidence Confronts Theory. Journal of Law, Economics, and Organization 6:345-80.

Spier, Kathryn E. 1992. The Dynamics of Pretrial Negotiation. Review of Economic Studies 59:103-8.

- 1994. Pretrial Bargaining and the Design of Fee-Shifting Rules. RAND Journal of Economics 25:197-214.

- 2007. Litigation. Pp. 259-342 in volume 1 of The Handbook of Law and Economics, edited by A. Mitchell Polinsky and Steven Shavell. Amsterdam: North Holland.

Terza, Joseph V., Anirban Basu, and Paul J. Rathouz. 2008. Two-Stage Residual Inclusion Estimation: Addressing Endogeneity in Health Econometric Modeling. Journal of Health Economics 27:531-43. 
Tullock, Gordon. 1980. Efficient Rent Seeking. Pp. 97-112 in Toward a Theory of the Rent Seeking Society, edited by James M. Buchanan, Robert D. Tollison, and Gordon Tullock. College Station: Texas A\&M University Press.

Viscusi, W. Kip. 1988. Product Liability and Risk Aversion. Journal of Legal Studies 17: 101-21.

Waldfogel, Joel. 1995. The Selection Hypothesis and the Relationship between Trial and Plaintiff Victory. Journal of Political Economy 103:229-60.

- 1998. Selection of Cases for Trial. Pp. 419-24 in volume 3 of The New Palgrave Dictionary of Economics and the Law, edited by Peter Newman. London: Macmillan Reference Ltd.

Watanabe, Yasutora. 2005. Learning and Bargaining in Dispute Resolution: Theory and Evidence from Medical Malpractice Litigation. Unpublished manuscript. Northwestern University, Kellogg School of Management, Evanston, Ill.

Yildiz, Muhamet. 2003. Bargaining without a Common Prior-an Immediate Agreement Theorem. Econometrica 71:793-811.

- 2004. Waiting to Persuade. Quarterly Journal of Economics 119:223-48.

Yoon, Albert. 2004. Mandatory Arbitration and Civil Litigation: An Empirical Study of Medical Malpractice Litigation in the West. American Law and Economics Review 6:95134. 